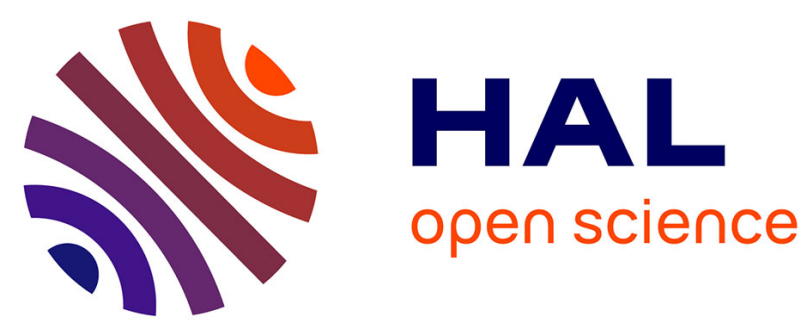

\title{
Effect of a Ni interlayer on microstructure and mechanical properties of WC-12Co cermet / SC45 steel friction stir welds
}

\author{
Marie Noëlle Avettand Fenoël, T. Nagaoka, H. Fujii, Roland Taillard
}

\section{To cite this version:}

Marie Noëlle Avettand Fenoël, T. Nagaoka, H. Fujii, Roland Taillard. Effect of a Ni interlayer on microstructure and mechanical properties of WC-12Co cermet / SC45 steel friction stir welds. Journal of Manufacturing Processes, 2019, Journal of Manufacturing Processes, 40, pp.1-15. 10.1016/j.jmapro.2019.02.032 . hal-02165682

\section{HAL Id: hal-02165682 \\ https://hal.univ-lille.fr/hal-02165682}

Submitted on 22 Oct 2021

HAL is a multi-disciplinary open access archive for the deposit and dissemination of scientific research documents, whether they are published or not. The documents may come from teaching and research institutions in France or abroad, or from public or private research centers.
L'archive ouverte pluridisciplinaire HAL, est destinée au dépôt et à la diffusion de documents scientifiques de niveau recherche, publiés ou non, émanant des établissements d'enseignement et de recherche français ou étrangers, des laboratoires publics ou privés.

\section{(ㄷ)(1) $\$$}

Distributed under a Creative Commons Attribution - NonCommerciall 4.0 International 


\title{
Effect of a Ni interlayer on microstructure and mechanical properties of WC-12Co cermet / SC45 steel friction stir welds.
}

\author{
M.-N. Avettand-Fènoël ${ }^{a^{*}}$, T. Nagaoka ${ }^{b}$, H. Fujii ${ }^{c}$, R. Taillard ${ }^{a}$ \\ a: Unité Matériaux Et Transformations (UMET), UMR CNRS 8207, \\ Université de Lille, 59655 Villeneuve d'Ascq, France
}

b: Osaka Research Institute of Industrial Science and Technology, Osaka 5368553, Japan

c: Joining and Welding Research Institute, Osaka University, Osaka 5670047, Japan

* Corresponding author - E-mail: marie-noelle.avettand-fenoel@univ-lille.fr

Tel: 33(0)320436927

Fax: 33(0)320434040

\begin{abstract}
WC-12Co cermet was friction stir lap welded with SC45 steel with or without different thicknesses of a Ni interlayer. The visualization of the material flow was rendered easy by the insertion of the Ni layer. Welding gives rise to the formation of Widmanstätten ferrite, low temperature pearlite, bainite, martensite and retained austenite in the nuggets of the joints. Some interdiffusion is noticed at the steel-cermet, steel-Ni and Ni-cermet interfaces, which leads, in particular, to the formation of oversaturated Co solid solutions in Fe or in $\mathrm{Ni}$. The increase in the Ni interlayer thickness is shown to lead to a more pronounced wear of the $\mathrm{Si}_{3} \mathrm{~N}_{4}$ tool and to a greater amount of retained austenite in the nugget. The mechanical tests finally suggest that the interface of the $\mathrm{Ni}$ bearing joints is of better quality than that of the $\mathrm{Ni}$ free joint.
\end{abstract}

Keywords: Lap friction stir welding; Cermet; Steel; Nickel interlayer; Material flow; Microstructure; Mechanical properties.

\section{Introduction}

The combination of hardness, wear resistance and thermal insulation, on the one hand, and of ductility and toughness, on the other hand, is rendered possible by joining cemented WC-Co-arbide cermet and steel. This association of materials with very distinct properties can be particularly relevant to develop machining tools heat and/or wear shields useful for engines or heat and thermomechanical processing.

Various processes such as including 1) brazing [1-9], 2) liquid state welding such as gas tungsten arc welding [10], tungsten inert gas (TIG) welding [11], laser welding [12-14], electron beam welding [15], 3) or solid state welding such as diffusion welding [16-20] and 4) hybrid processes such as TIG brazing [21], laser TIG welding [22] or high velocity oxygen fuel thermal spraying combined with friction stir processing [23] are used to join both kinds of materials [1-23], as already reported by the present authors [24]. Some surface treatments such as high velocity oxygen fuel spraying [25] and additive manufacturing processes like cold spray [25-2626-27] are also utilized to realize a cermet - steel assembly. However, given the difference between the physico-chemical (Table 1) and mechanical properties of both materials, joining cermet with steel remains a challenge. Three key issues must indeed be realized. They deal with 
1) the wettability of the cermet surface by the metal in the cases of brazing and liquid state welding,

2) the difference in the coefficients of thermal expansion (CTE) of both materials originating some residual stresses, and

3) the formation of brittle interfacial phases such as $\mathrm{Fe}_{3} \mathrm{~W}_{3} \mathrm{C}$ and/or $\mathrm{Co}_{3} \mathrm{~W}_{3} \mathrm{C}, \mathrm{Co}_{2} \mathrm{~W}_{4} \mathrm{C}$, $\mathrm{Co}_{4} \mathrm{~W}_{2} \mathrm{C} \eta$ phases $[4,9,12,14,15]$.

All these factors can entail reduced mechanical properties of the joint. Different solutions to tackle independently these three issues were detailed in our previous paper [24]. In particular, the wettability can be enhanced by 1) using an active filler metal with a judicious chemical composition such as a $\mathrm{Cu}-\mathrm{Zn}-10 \mathrm{Ni}$ [7], a 70Cu-30Zn [5] or a $\mathrm{Ag}-\mathrm{Cu}$ filler [3], 2) coating cermet with $\mathrm{Ni}$ [4] or steel with $70 \mathrm{Ni}-30 \mathrm{Cu}$ [16] or 3) coating a $\mathrm{Cu}-\mathrm{Zn}$ braze interlayer with $\mathrm{Ni}$ [4]. The stress concentration at the joint interface can be relieved for instance by coating the cermet with $\mathrm{Ni}[4, \mathbf{5}, \mathbf{1 7}, \mathbf{1 9}$, by using an interlayer of $\mathrm{Ni}[18,20]$, Ni$\mathrm{Cu}$ [18] or Ni-Cr in an $\mathrm{Ag}$ based filler metal [21] or a bilayer of $\mathrm{Cu}$ alloy-amorphous $\mathrm{Ni}$ alloy and oil cooling after brazing $[\mathbf{1 , 8}$ ] or a graded composite [5] or a $\mathrm{Ag}+\mathrm{Ni}+\mathrm{Co}$ filler alloy $[\mathbf{1 , 6}]$, by increasing the proportion of steel in the joint [18] or by applying a post heat treatment after laser [12] or electron beam [15] welding. The use of solid state joining processes can finally avoid the issue of wettability and limit the formation of brittle interfacial phases. In a previous study, the authors investigated the effect of the axial force on the FSW tool wear and contamination, as well as on the microstructure and mechanical properties of the SC45 steel $\mathrm{WC} / 12 \mathrm{Co}$ cermet lap friction stir joints [24]. A load increase from 9.80 to $14.70 \mathrm{kN}$ was shown to extend the solid solution areas at the steel-cermet interface. In addition, the lap shear tensile strength of the designed joints was shown to be greater [24] than its $400 \mathrm{MPa}$ highest value for most of the $\mathrm{WC} / \mathrm{Co}$ - steel joints developed by other processes $[\mathbf{2}, \mathbf{4}, \mathbf{5}, \mathbf{8 , 9}, \mathbf{1 5}-16$, 18-21]. More particularly, the joint with a load of $12.25 \mathrm{kN}$ was characterized by the greatest shear lap tensile strength close to $750 \mathrm{MPa}$. Only laser joint with an Invar interlayer [14] and diffusion joint with a $\mathrm{Cu} / \mathrm{Ni}$ bilayer [17] reached respectively a bending strength of $981 \mathrm{MPa}$ and a shear strength of $600 \mathrm{MPa}$, respectively. Nevertheless, the friction stirred joints present a low ductility [24].

In order to attempt to increase the plasticity of such friction stirred joints, the current work consists in inserting a Ni interlayer at the WC/12Co cermet - SC45 steel interface before joining the stacking by FSW. The easier plastic accommodation generated by the presence of Ni may reduce the problem of the CTE discontinuity, as proven in other studies [14] since the difference in the CTE of S45C steel and WC/12Co cermet (Table 1) can generate some defects and some residual stresses at the joint interface; a sudden change in the CTE can indeed generate residual stresses and the more important the larger the gap is [272828-29]. An addition of an interlayer of $\mathrm{Ni}$ is also shown to improve the mechanical strength of cermet - steel joint developed either by brazing [5] or by diffusion welding $[17, \mathbf{1 9}]$. Besides Ni is alse highly soluble in both Fe and $\mathrm{Co}$ [2930] which could further prevent the formation of $\eta \mathrm{Co}_{\mathrm{x}} \mathrm{Fe}_{\mathrm{y}} \mathrm{W}_{\mathrm{z}} \mathrm{C}$ brittle interfacial phases [24] and then contribute to suitable interfacial joint strength and ductility. Moreover, the Ni addition prevents the formation of a Co depleted zone. The same parameters as in a previous work [24] are considered, except for the cermet thickness which is doubled and the insertion of a Ni filler at the cermet-steel interface. The investigation aims

- to show the feasibility of welding this stacking by friction stirring,

- to analyze the effect of $\mathrm{Ni}$, which is an austenite stabilizing element on the joint microstructure and

- to characterize the effect of the Ni interlayer thickness on 1) the material flow, 2) the microstructure of both the processed zone and the interfacial zone at various scale lengths and 3) the joints mechanical properties. 
It should therefore enable us to appreciate the pros and cons of inserting a Ni filler on the joint performances.

Table 1: Properties of SC45 steel, pure Ni and WC-12Co cermet [29-3130-32].

\begin{tabular}{|c|c|c|c|c|c|}
\hline Material & $\begin{array}{l}\text { Density } \\
\left(\text { g.cm }{ }^{-3}\right)\end{array}$ & $\begin{array}{c}\text { Melting } \\
\text { temperature } \\
\left({ }^{\circ} \mathrm{C}\right)\end{array}$ & $\begin{array}{c}\text { Coefficient of } \\
\text { thermal expansion } \\
(\mathrm{CTE}) \\
\left({ }^{\circ} \mathrm{C}^{-1}\right)\end{array}$ & $\begin{array}{l}\text { Specific heat } \\
\text { capacity } \\
\left(\mathrm{J}^{\mathrm{kg}} \mathrm{kg}^{-1} \cdot \mathrm{K}^{-1}\right)\end{array}$ & $\begin{array}{c}\text { Thermal } \\
\text { conductivity } \\
\left(\mathrm{W} \cdot \mathrm{m}^{-1} \cdot \mathrm{K}^{-1}\right)\end{array}$ \\
\hline SC45 steel & 7.8 & 1520 & $\begin{array}{c}1410^{-6} \\
\text { over }\left[20^{\circ} \mathrm{C}-500^{\circ} \mathrm{C}\right]\end{array}$ & 486 & 49.8 \\
\hline $\mathrm{Ni}$ & 8.9 & 1455 & $\begin{array}{c}13.310^{-6} \\
\text { over }\left[20^{\circ} \mathrm{C}-100^{\circ} \mathrm{C}\right] \\
\end{array}$ & 456 & 74.9 \\
\hline $\begin{array}{l}\text { WC-12Co } \\
\text { cermet }\end{array}$ & 14.0 & 1470 & $\begin{array}{c}5.910^{-6} \\
\text { over }\left[20^{\circ} \mathrm{C}-800^{\circ} \mathrm{C}\right]\end{array}$ & $212-221$ & $76-83$ \\
\hline
\end{tabular}

\section{Experimental procedure}

The base materials were $\left(15 * 45 \mathrm{~mm}^{2}\right)$ plates of SC45 steel $(2.4 \mathrm{~mm}$ thick, mean hardness of $288 \mathrm{HV} 0.05)$, WC-12Co cermet ( $2 \mathrm{~mm}$ thick, mean hardness of $1782 \mathrm{HV} 0.05$ ) and pure nickel (mean hardness of $286 \mathrm{HV} 0.05$ with a thickness of $0,0.05,0.1$ or $0.2 \mathrm{~mm}$ ). Their chemical compositions are indicated in Table 2. Before FSW, the surface of the sintered cermet was polished up to $1 \mu \mathrm{m}$ sized diamond paste. The surface roughness Ra of the cermet is $0.7 \mu \mathrm{m}$ while that of the steel is $1.2 \mu \mathrm{m}$. Those of Ni sheet with thickness of $0.05,0.1$ and $0.2 \mathrm{~mm}$ are $0.5,0.5$ and $0.2 \mu \mathrm{m}$, respectively. The materials were friction stir welded in a lap configuration where the steel is on the top and $\mathrm{Ni}$ was eventually inserted at the interface between the steel and the cermet. Four joints were produced namely, one Ni free joint and three $\mathrm{Ni}$ bearing joints differing by the $\mathrm{Ni}$ interlayer thickness (figure 1). The stacking was clamped to a $\mathrm{H} 13$ tool steel backing plate before friction stir welding. Joining was performed under argon whose flow was stopped at the beginning of tool extraction. A tool made of sintered $\mathrm{Si}_{3} \mathrm{~N}_{4}$ was used. The selection of the $\mathrm{Si}_{3} \mathrm{~N}_{4}$ material is justified by both its low cost and high ability to be sintered. Silicon nitride is also well known as an adequate material for applications where strength at high temperature, toughness, thermal shock resistance, wear resistance and corrosion resistance are needed. The tool had a concave shoulder with a $12 \mathrm{~mm}$ diameter and its tapered conical probe was unthreaded with a 4 (3.6) $\mathrm{mm}$ diameter at its root (rounded tip) and a length of $2.4 \mathrm{~mm}$. During the process, the load applied on the $3^{\circ}$ backward tilted tool was $12.50 \mathrm{kN}$; the tool clockwise rotational speed $(\omega)$ was $800 \mathrm{rpm}$ while its advancing speed (v) was $50 \mathrm{~mm} / \mathrm{min}$, the welding direction being parallel to the rolling direction of the steel. These settings led indeed to the best S45C/WC-12Co joints in our previous work [24].

Table 2: Chemical composition of the base materials.

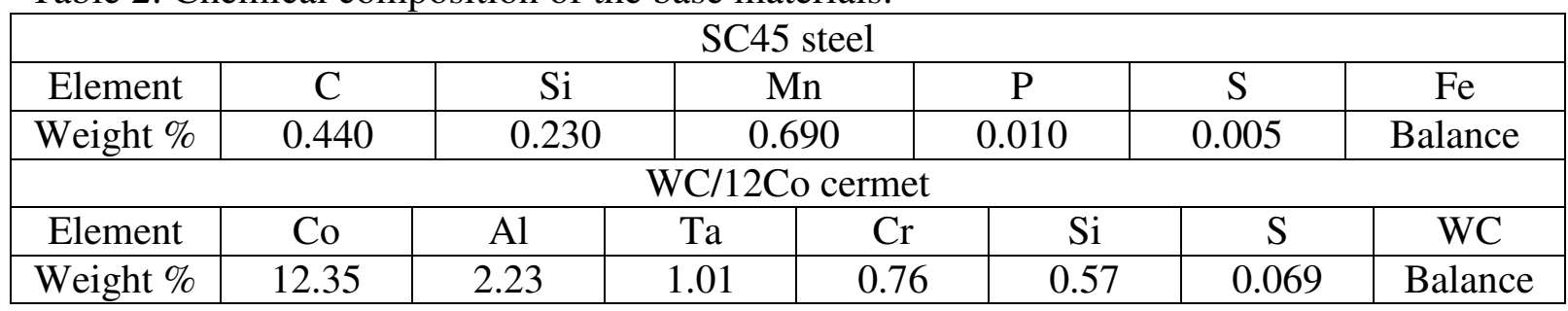




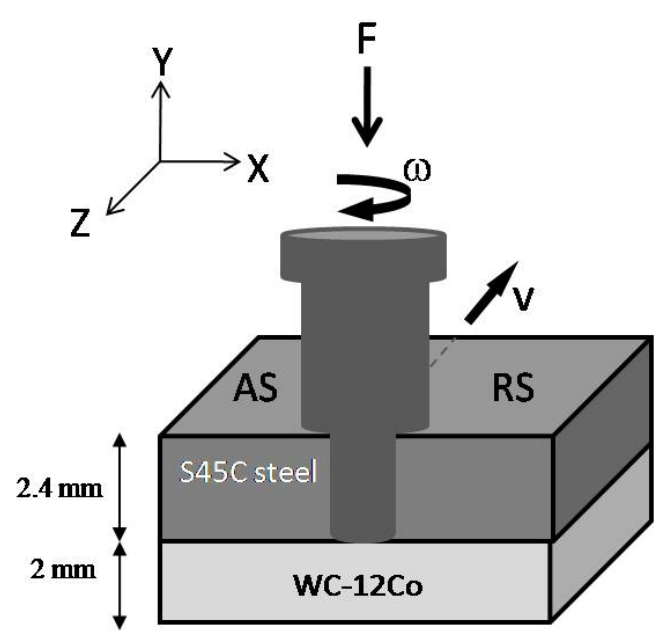

$\mathrm{Ni}$ free joint

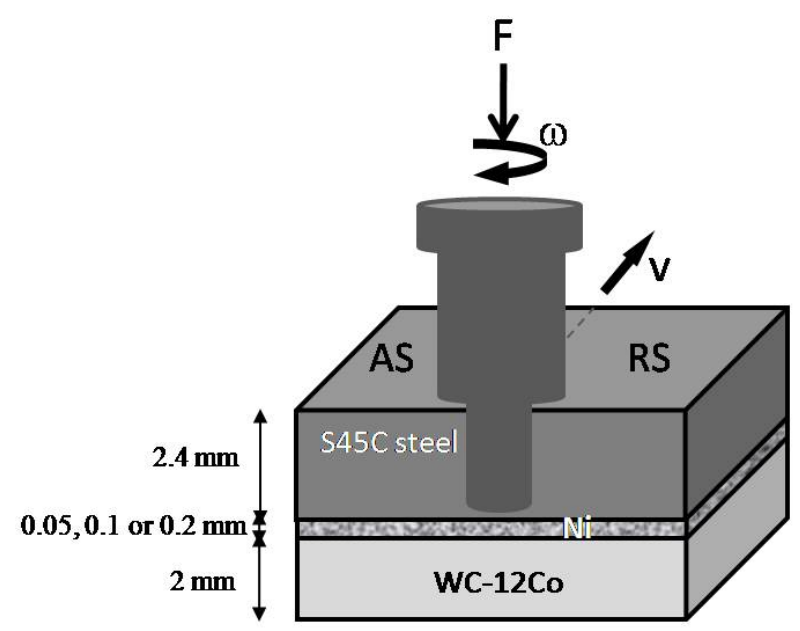

Ni bearing joint

Figure 1: Lap FSW process settings for Ni free and Ni bearing joints. AS and RS are the abbreviations for the advancing and retreating sides, respectively.

Two K-type thermocouples with a $0.5 \mathrm{~mm}$ diameter were inserted in slots of $0.7 \mathrm{~mm}$ diameter machined in the plates to weld. One thermocouple was inserted at $2.5 \mathrm{~mm}$ from the weld centre [i.e., in the heat affected zone (HAZ) of the joint] on the AS of steel and just above the $\mathrm{Ni}$ plate, while the other one was placed at the weld centre in the cermet just below the $\mathrm{Ni}$ layer (figure 2).

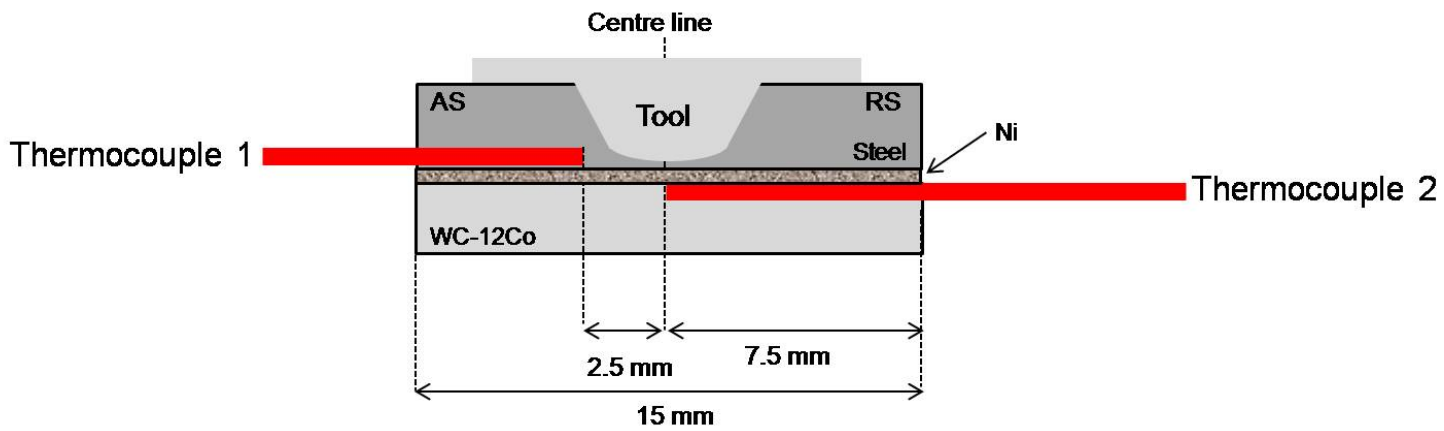

Figure 2: Thermocouple locations in the $(\mathrm{X}, \mathrm{Y})$ transverse cross section of the joint.

Before microstructural characterization, the joints were cut by electrical discharge machining and then grinded and polished up to a $1 \mu \mathrm{m}$ diamond paste grade.

The tool, the base materials and the joints were analyzed by light microscopy, scanning electron microscopy (SEM) in the secondary (SE) or back scattering electron (BSE) mode and $\mathrm{X}$-ray energy dispersive spectroscopy (EDX). In order to reveal the steel microstructure, various etchants were used. Benscoter and Marder reagent (nital etchant followed by $10 \%$ aqueous sodium metabisulfite etchant) colored the retained austenite in white, martensite in black and ferrite in white off. Nital reagent (ethylic alcohol and $1 \%$ nitric acid) was used to differentiate the ferrite, pearlite, bainite and martensite. Dino reagent $(140 \mathrm{~mL}$ of water, 100 $\mathrm{mL}$ of hydrogen peroxide, $4 \mathrm{~g}$ of oxalic acid, $2 \mathrm{~mL}$ of sulphuric acid, $1.5 \mathrm{~mL}$ of hydrofluoric acid) revealed acicular ferrite and the grain boundaries. Leperra reagent (50 vol\% [4\% picric acid in ethylic alcohol] +50 vol. $\%$ [water with $1 \%$ of sodium metabisulphite] colored martensite in white, bainite and pearlite in dark brown and ferrite in light brown. 
For Scanning Transmission Electron Microscopy ((S)TEM) /EDX analyses with a probe size of $10 \mathrm{~nm}$ and electron diffraction analyses, thin foils were cut from the joints by the Focused Ionic dual Beam (FIB) technique.

$\mathrm{X}$-ray diffractometry $(\mathrm{XRD})$ was performed using a cobalt radiation $[\lambda \mathrm{Co}(\mathrm{K} \alpha 1)=1.78901 \AA]$ in a Bragg Brentano configuration.

Concerning the mechanical tests, microhardness was measured under a $50 \mathrm{~g}$ load on the transverse cross-sections of the joints at $500 \mu \mathrm{m}$ intervals along the $\mathrm{X}$ and $\mathrm{Y}$ axes. Three shear lap tensile tests were carried out by type of joint following the recommendations of the JIS Z3198-5 standard (figure 3). Shear tool rate was $1 \mathrm{~mm} / \mathrm{min}$.
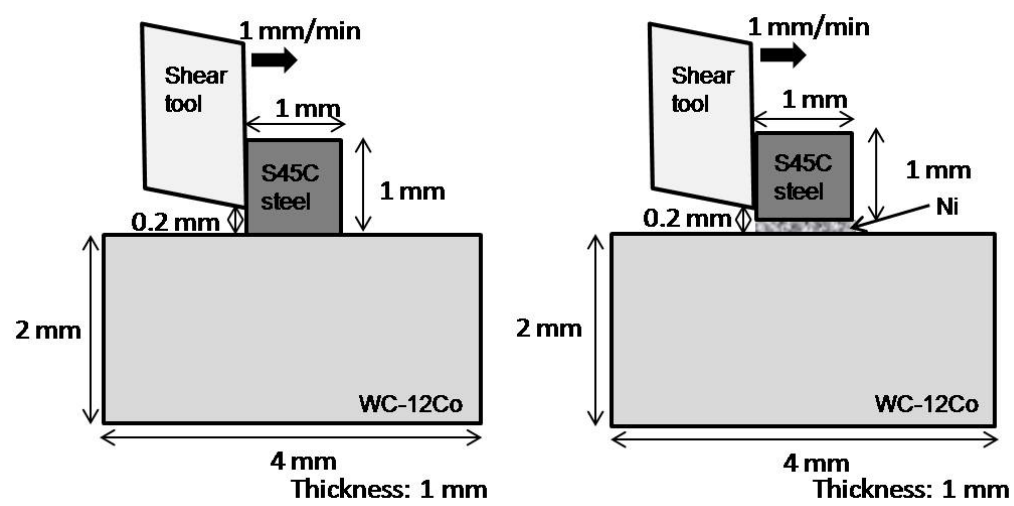

Figure 3: Shear lap tensile test setting.

\section{Results}

3.1.Thermal profiles - The temperature profiles, the evolution of the peak temperatures and the times needed to reach the peak temperatures are displayed in figure 4 . The temperatures and times at the peaks are essentially constant whatever the sample and the Ni thickness even if some small erratic fluctuations are noted. The differences are however very slight according to the fact that thermocouples may move a little during the process. In addition, due to the very close thermal conductivities of $\mathrm{Ni}$ and cermet (see table 1), the different thicknesses of the $\mathrm{Ni}$ interlayer do not modify neither the peak temperatures and peak times nor the global aspect of thermal cycles. For any kind of joint, the temperature of the cermet remains lower than the HAZ temperature on the AS of the steel, which is in agreement with the thermal properties of both materials (Table 1) and the fact that the tool is not inserted in the cermet. 

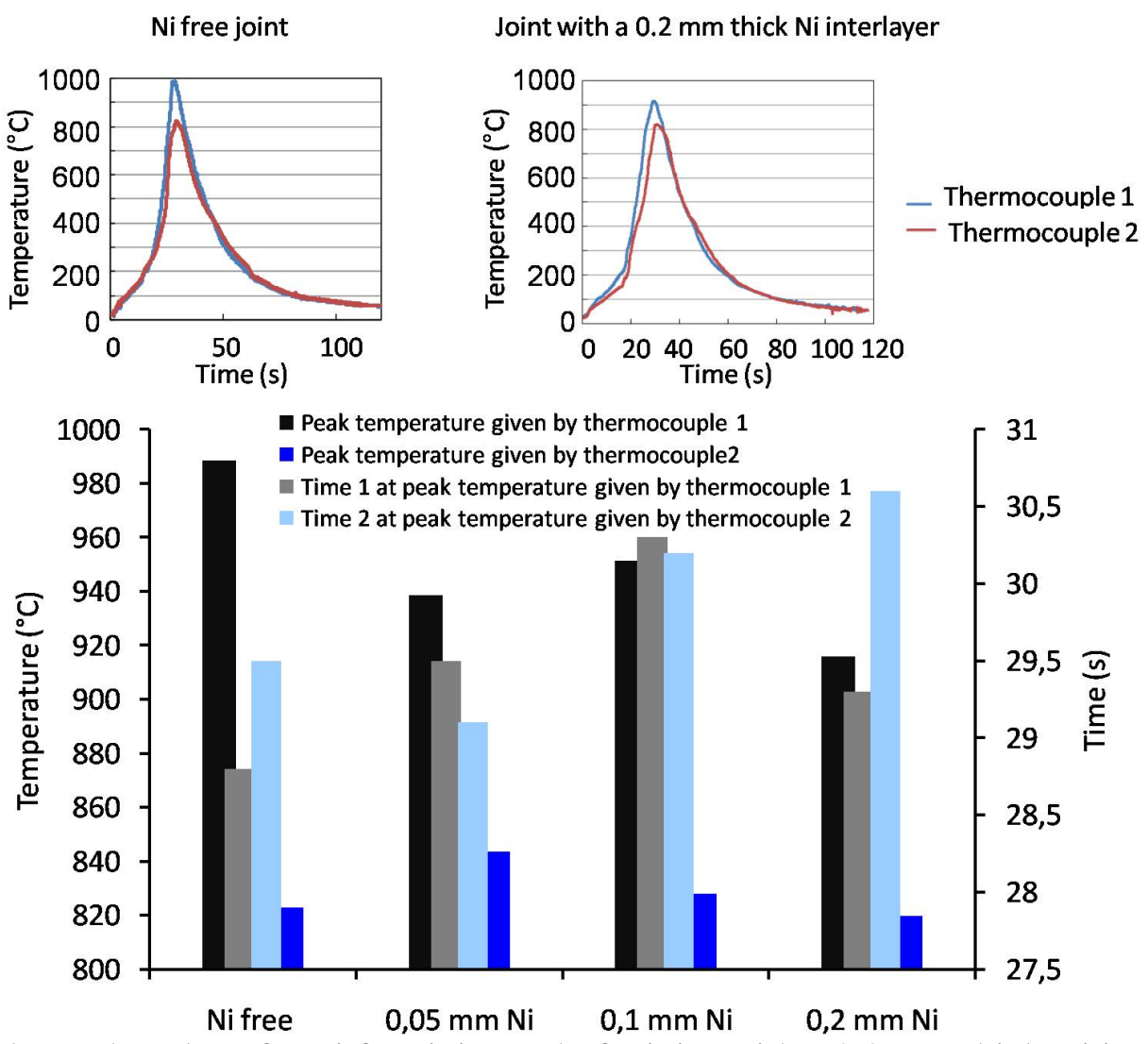

Figure 4: Thermal cycles of a Ni free joint and of a joint with a $0.2 \mathrm{~mm}$ thick Ni interlayer, and histogram of the peak temperatures and times at the peak temperatures $v s$. the joint nature. As a reminder, thermocouple 1 is located in the steel HAZ and thermocouple 2 is in the cermet at the weld centre close to the interface.

3.2. Base materials - SC45 steel is composed of proeutectoid ferrite and pearlite with a grain size of approximately $20 \mu \mathrm{m}$ (figures $5 \mathrm{a} \&$ and $5 \mathrm{~b}$ ). The WC-12Co cermet is comprised of 0.5 $\mu \mathrm{m}$ mean sized WC grains (figure 5c) presenting some mechanical twins (figure $5 \mathrm{~d}$ ) and bound with $\mathrm{Co}$ (figure 5c). The pure Ni interlayer is made of 3 to $7 \mu \mathrm{m}$ diametered grains. 

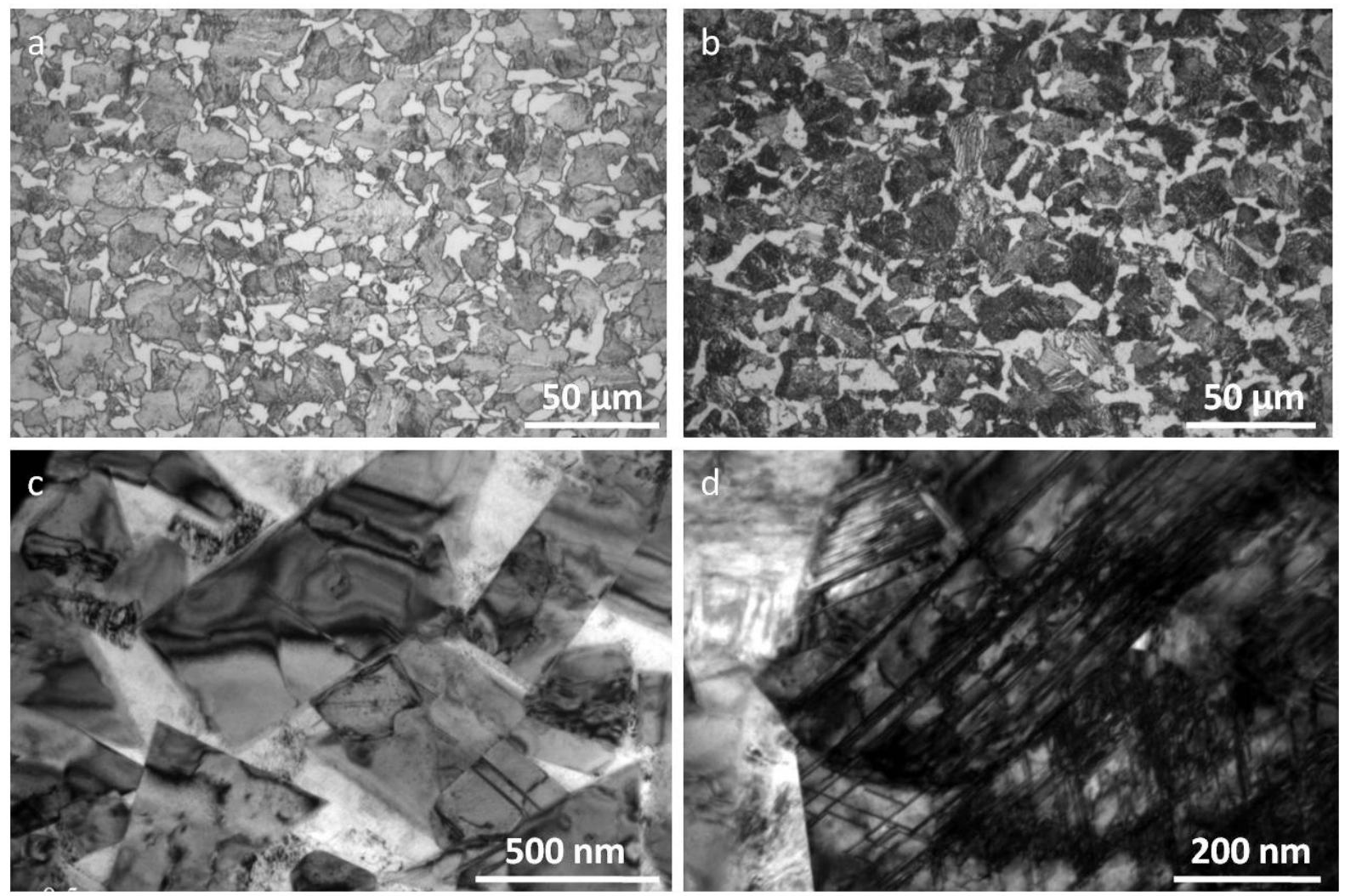

Figure 5: Transverse cross-sections of the SC45 base steel etched with a) the Dino and b) the nital reagent (light microscopy), and of the WC-12Co cermet (c and d) (TEM). The bright phase in figures $\mathrm{c}$ and $\mathrm{d}$ is the Co binding phase.

3.3. Joint surface, keyhole and tool wear - The global features of the joints are displayed in figure 6a. The flash is more developed on the RS than on the AS, and all the more that the joint is $\mathrm{Ni}$ free. This is very likely due to the higher temperature measured on the RS than on the AS. A significant difference of $75^{\circ} \mathrm{C}$ was indeed measured between RS and AS in our previous study of S45C/WC-12Co FSW joints [24]. In addition, since the steel HAZ temperature on the AS tends to decrease with the Ni layer thickness (figure 4, thermocouple 1), the temperature on the RS of the steel HAZ is also expected to decrease with the Ni thickness. Such an observation would be consistent with the trend towards reduction of the flash extent with an increase in the Ni thickness.

Besides, the surface of the joints, consisting of small grains with a size close to $3.5 \mu \mathrm{m}$ (figure $6 \mathrm{c}$ ), shows some half crowns. These grooves are spaced $62.5 \mu \mathrm{m}$ apart (figures $6 \mathrm{~b}$ and $6 \mathrm{c}$ ) which corresponds to the welding pitch defined as the ratio between the advancing speed and the rotational speed. Some less significant grooves with the same periodicity are also observed (figure $6 \mathrm{~b}$ ). These reliefs of secondary amplitude are very likely due to periodical vibrations or transient tool-sample stickings during welding aided or not by the roughness of the probe surface since some traces of adhesion are observed on the crowns ridges in the wake of the tool (see yellow arrow in figure 6c).

With regard to the keyholes surfaces, their aspect differs whether the joint is $\mathrm{Ni}$ free or contains a $\mathrm{Ni}$ interlayer (figure 7). In the first case, the bottom of the keyhole is cracked (figures 7d) and the pin had not touched the cermet according to the EDX analyses. In the second case, the surface at the bottom of the keyhole is dulled since the pin had touched the Ni interlayer (figures 7b, 7c, 7e and 7f). At some locations (like for instance the bright trails in figure 7e), the pin edge has even reached the cermet as proved by the EDX analyses. Some contamination of the pin by $\mathrm{Ni}$ and cermet was further proved by X-ray diffractometry (figure 
8). Some traces of the cermet were also detected by EDX at the borders of the keyholes and at the surface of the flashes (figure 9a), which is consistent with the mechanism of formation of the flashes previously detailed [24].
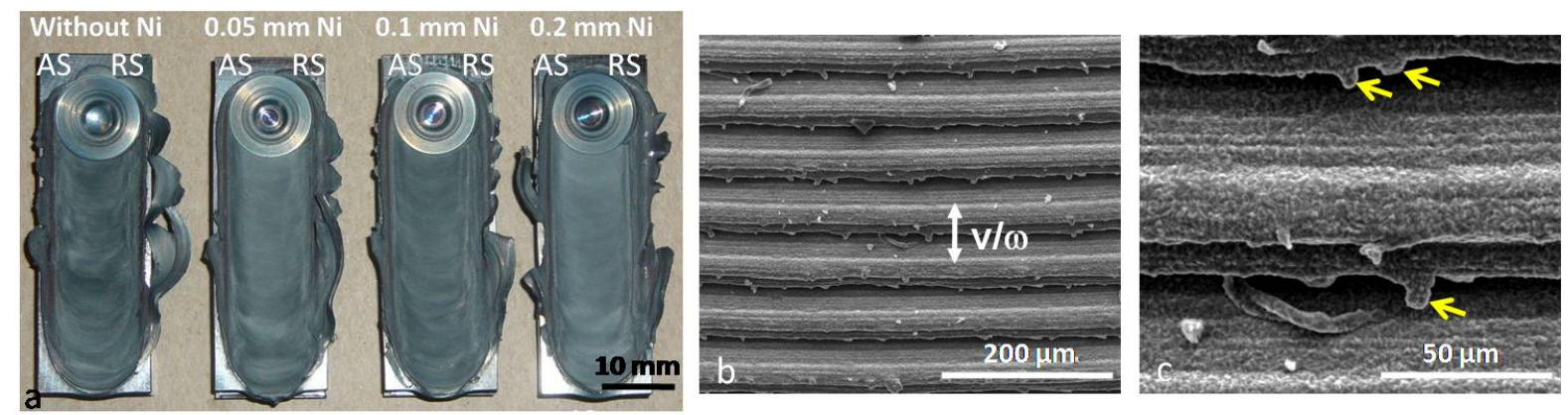

Figure 6: a) Global top view of the joints $v s$. the Ni interlayer thickness; b) typical details of a joint top surface and c) of its half crowns (joint with a $0.1 \mathrm{~mm}$ thick Ni interlayer) (SE/SEM).

In addition, some debris of iron oxides (arrowed in figure 7a) are identified in the keyhole as well as on the FSW probe surface (figure 8, see the rusted surface of the tool pin, figure $9 \mathrm{~b}$ ). These debris originate from the oxidation of the tool as the argon flux was stopped between successive weldings after the tool extraction. Besides, some fragments of $\mathrm{Si}_{3} \mathrm{~N}_{4}$ sintered powder particles originating from the FSW tool are observed at the interior of the keyhole (figure 9c). It is worthy to note that the $\mathrm{Si}_{3} \mathrm{~N}_{4}$ fragments are the more numerous, the thicker the $\mathrm{Ni}$ interlayer is. However, this observation cannot be explained by a significant reduction in temperature with the Ni thickness increase (figure 4). It has rather to do with the tool damage due to thermal and mechanical cyclic solicitations because of the successive welding of the different coupons with the same tool. All these results prove the tool wear during welding (figure 9b). In accordance, the tool is also fractured and shows some traces of adhesion and oxidation.
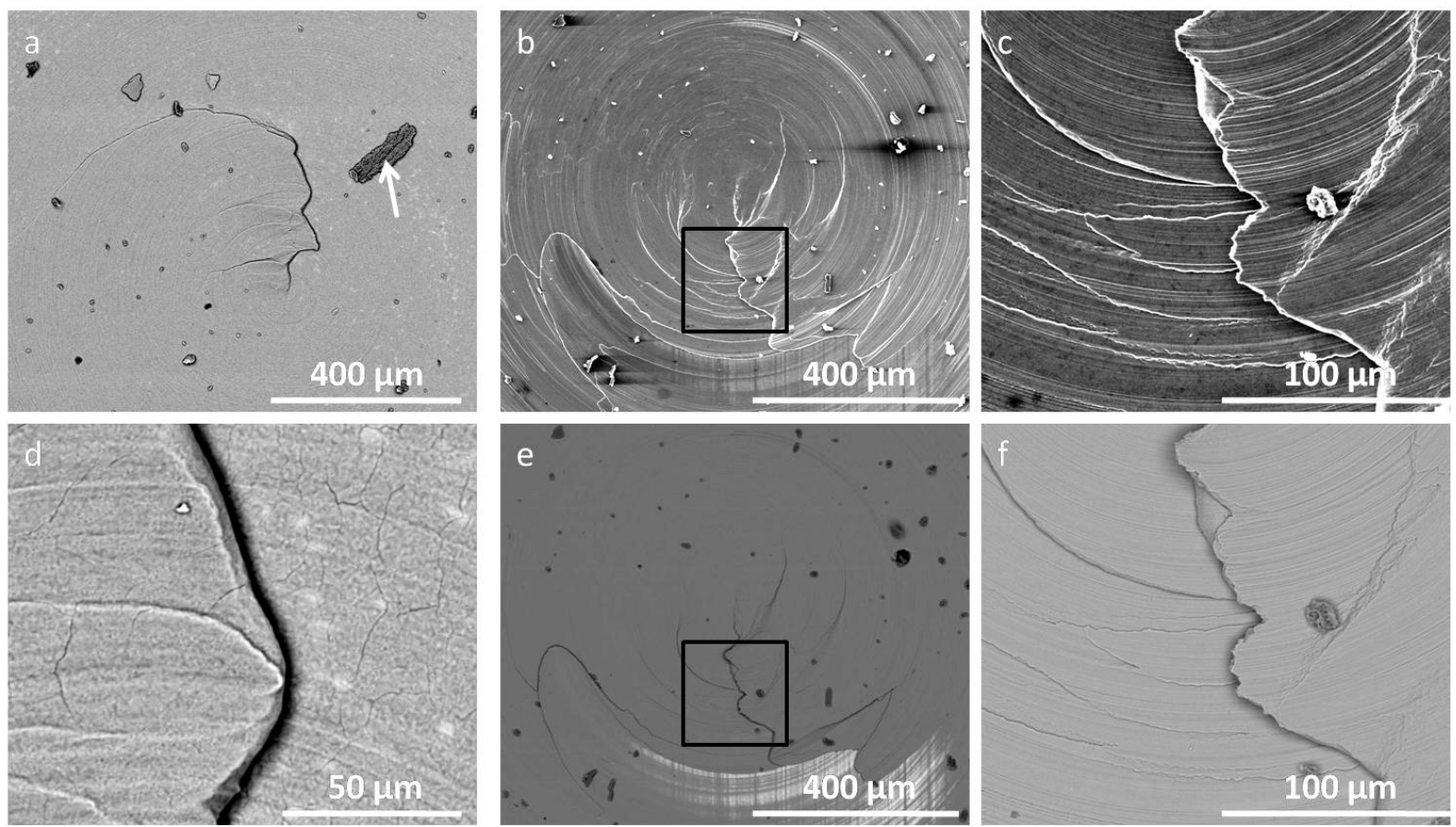
Figure 7: Details at the bottom of the keyhole a) and d) of the Ni-free joint (SE and BSE/SEM, respectively), b) and e) of the joint with a $0.1 \mathrm{~mm}$ thick Ni interlayer, c) and d) enlargement of the zones encircled in figures b) and e), respectively.

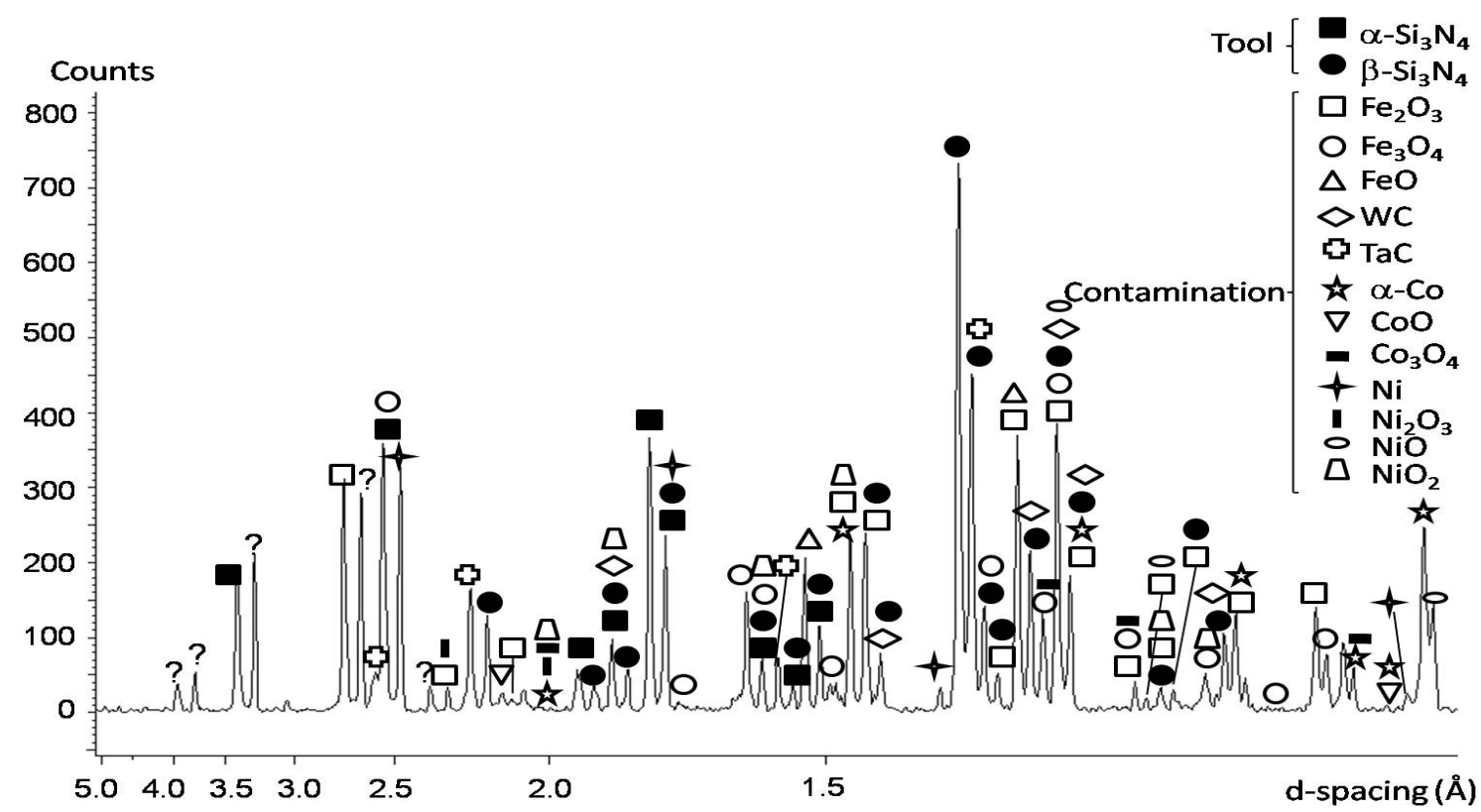

Figure 8: X-ray diffraction pattern showing the contamination of the pin due to welding.
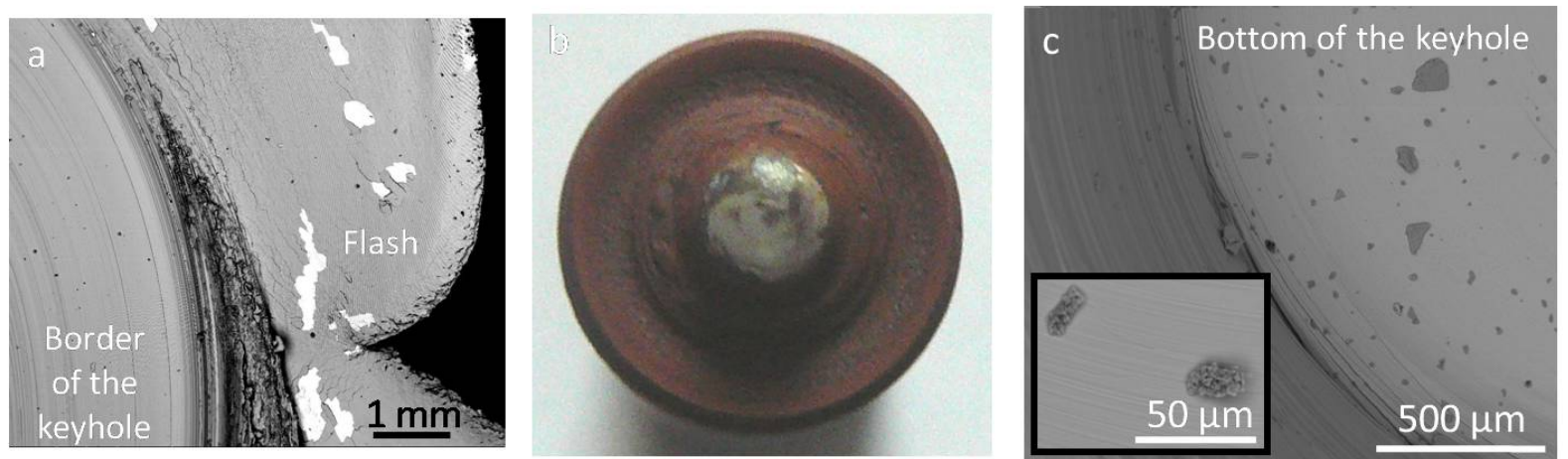

Figure 9: a) Contamination detected on the flash at the border of the keyhole of the Ni free joint (BSE/SEM). b) Tool tip after welding. c) Numerous debris at the bottom of the joint keyhole with a $0.2 \mathrm{~mm}$ thick $\mathrm{Ni}$ interlayer. The insert depicts some agglomerates of $\mathrm{Si}_{3} \mathrm{~N}_{4}$ powder grains originating from the tool (BSE/SEM).

3.4. Material flow - Whatever the joint, it is composed of a stirred zone bordered by a heat affected zone (HAZ). A thermomechanical affected zone has not been detected at the HAZbase material interface. These zones have actually experienced distinct thermal (for the HAZ) and thermomechanical (for the nugget) histories according to their distance from the tool. There is no effect of the Ni thickness on the width of the processed zone (figure 10) which seems to be consistent with the quasi invariance of the temperature peaks (figure 4).

Irrespective of the joint, the flashes are more significant on the retreating side (RS) than on the advancing side (AS) (figures 6a and 10), which is as aforesaid consistent with the higher temperatures on the RS [24]. 
It is essentially steel and $\mathrm{Ni}$ that experienced the tool motion as displayed in figures 10 and 11. In the absence of $\mathrm{Ni}$ at the steel-cermet interface and for the smallest thickness of $\mathrm{Ni}$ $(0.05 \mathrm{~mm})$, it is worthy to note that the detection of onion rings is not obvious in the nugget (figure 10). In contrast, in presence of a sufficient thickness of $\mathrm{Ni}$, i.e., from $0.1 \mathrm{~mm}$ in the present work, the onion rings can easily be observed (figures $10 \&$ and 11).

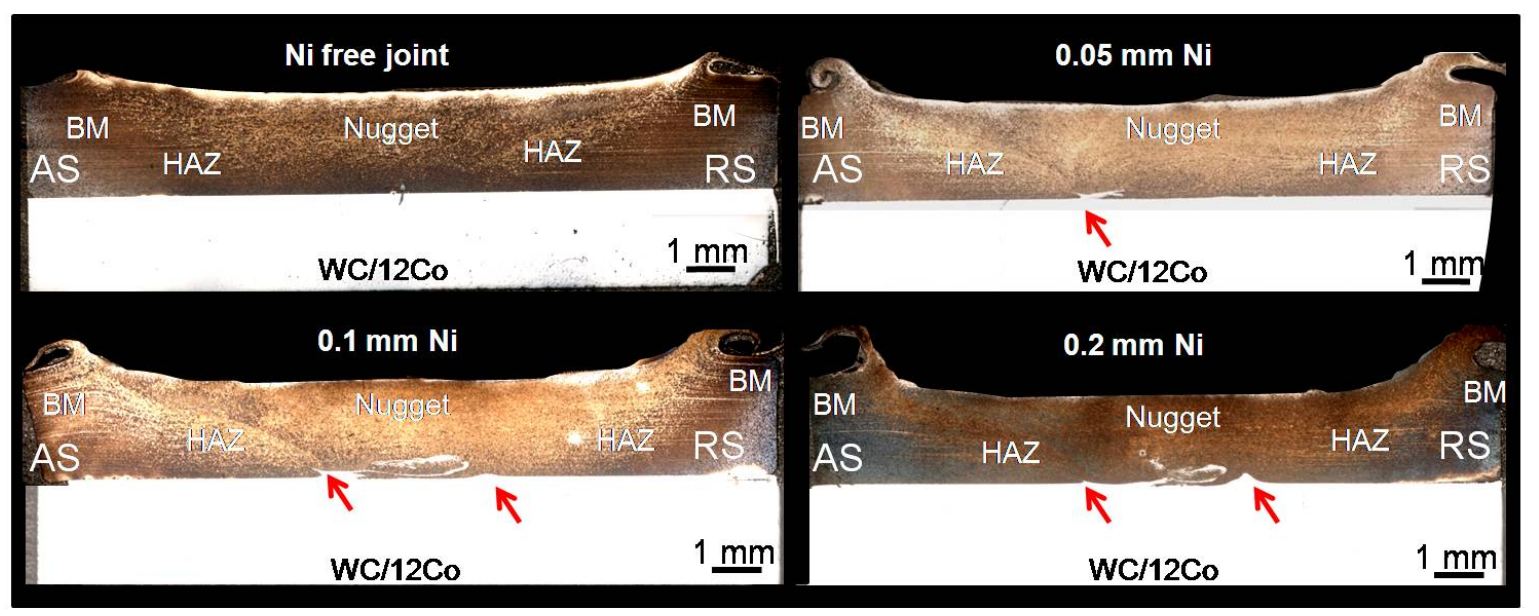

Figure 10: Transverse cross-sections of the different joints etched with the Benscoter and Marder reagent (light microscopy). BM and HAZ are the abbreviations for base material and heat affected zone, respectively.

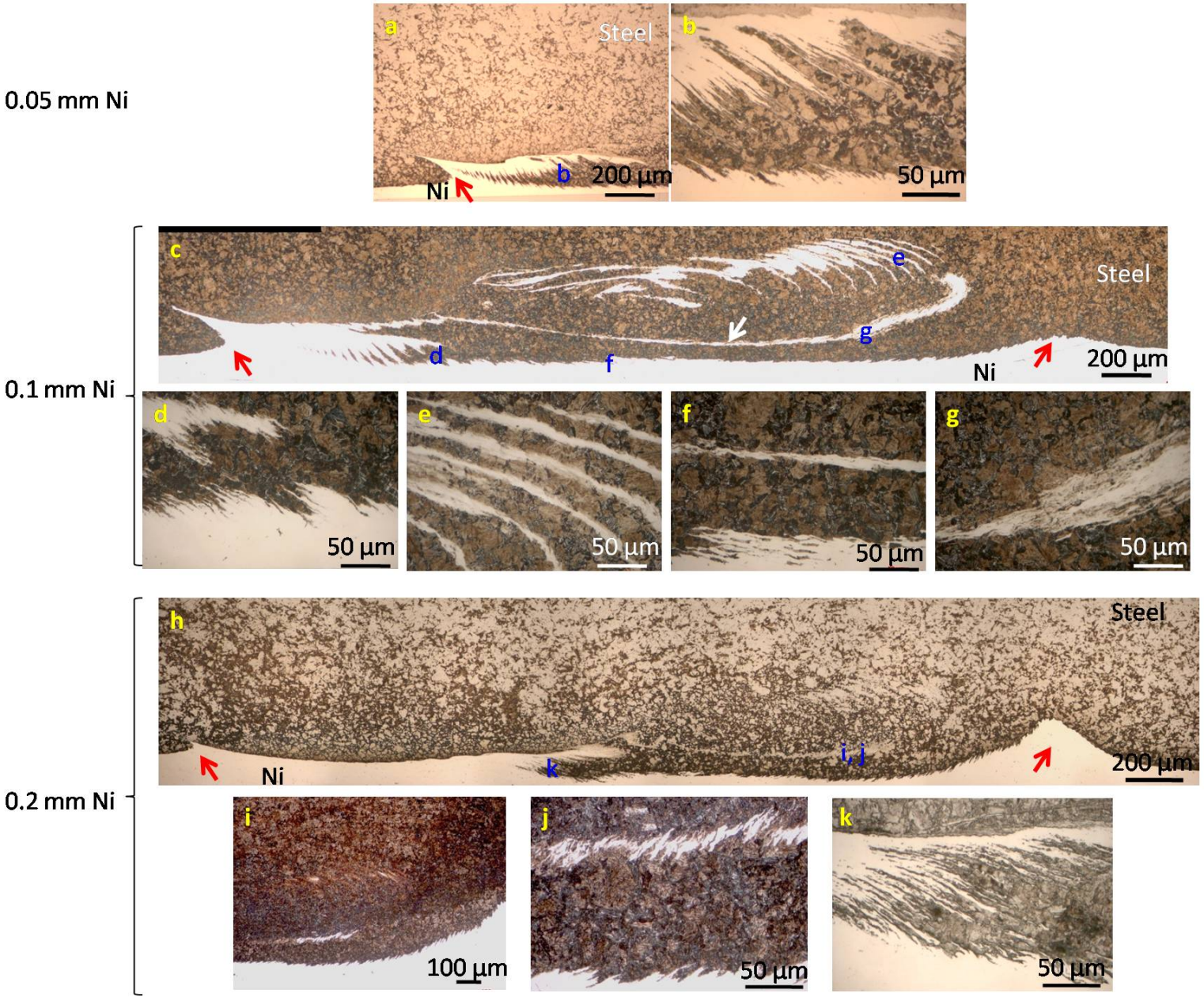


Figure 11: Details of the processed zones in the transverse cross sections depicted in figure 10 for the Ni bearing joints with a $0.05 \mathrm{~mm}$ thick interlayer ( $\mathrm{a} \&$ and $\mathrm{b}$ obtained with Leperra etchant), a $0.1 \mathrm{~mm}$ thickness (c, d, e, f \& and g obtained with Benscoter and Marder etchant) and a $0.2 \mathrm{~mm}$ thickness (h obtained with Leperra etchant, $\mathrm{i} \&$ and $\mathrm{j}$ get with nital etchant and $\mathrm{k}$ get with Dino etchant) (light microscopy).

The Ni interlayer indeed plays the role of a marker for the material flow which has occurred during the process. Moreover, the evolution of the transverse cross-sections of the Ni bearing joints according to the Ni interlayer thickness enable us to follow and understand the phenomenological mechanism of the onion ring zone formation. The onion rings are irregularly spaced by a distance which differs very often from the welding pitch (referred as the ratio between the welding speed and the rotational speed) (figures 11c and e), as already noted in a previous work [3233]. In the present case, it is worthy to note that the nugget is transversally asymmetrical and shifted towards the RS. Indeed, during FSW, the material is dragged from the AS towards the RS that is warmer than the AS, which renders the material flow easier on this RS. The onion rings are more asymmetrical along the joint depth; actually, there is an exacerbated stacking of the chips close to the interface where the Ni cools more rapidly than the steel and the cermet is less malleable than both Ni and steel (Table 1).

Besides, the morphology of the interfaces with the Ni changes according to the surrounding material. At the Ni-steel interface, some tongues are turned towards either the AS or the RS according to their AS or RS location (figures 11c and h). The Ni-steel interface is thus uneven (figures $11 \mathrm{~b}, \mathrm{c}, \mathrm{d}, \mathrm{f}, \mathrm{h}, \mathrm{i}, \mathrm{j}, 12 \mathrm{a}, 12 \mathrm{~b}$,), which is consistent with a previous result indicating that the pin was in contact with Ni. Conversely, the Ni-cermet interface is rather flat at a mesoscopic scale (figure 13). The latter observation proves that the pin did not touch the cermet during the stationary state of welding. In addition, two nickel hook precursors (see red arrows in figure 10 and $11 \mathrm{a}, \mathrm{c}$ and $\mathrm{h}$ ), are formed on each side of the stirred zone. They became the more marked as the Ni interlayer thickness increases. These hooks precursors, which can contribute to mechanical anchoring, are usually observed during friction stir spot welding [33]. They also enable us to visualize the extent of the zone processed by the pin at its tip. The lateral dimensions of this zone are approximately 3.4 to $3.7 \mathrm{~mm}$, according to the Ni bearing joint, which is consistent with the pin tip diameter of $3.6 \mathrm{~mm}$.

Besides, it is worth noting that the extent of the Ni onion rings along the joint depth increases from 0.32 to $0.49 \mathrm{~mm}$ from the $\mathrm{Ni} / \mathrm{steel}$ interface when the $\mathrm{Ni}$ interlayer thickness increases from 0.05 to $0.2 \mathrm{~mm}$ (figures $10 \&$ and 11 ).
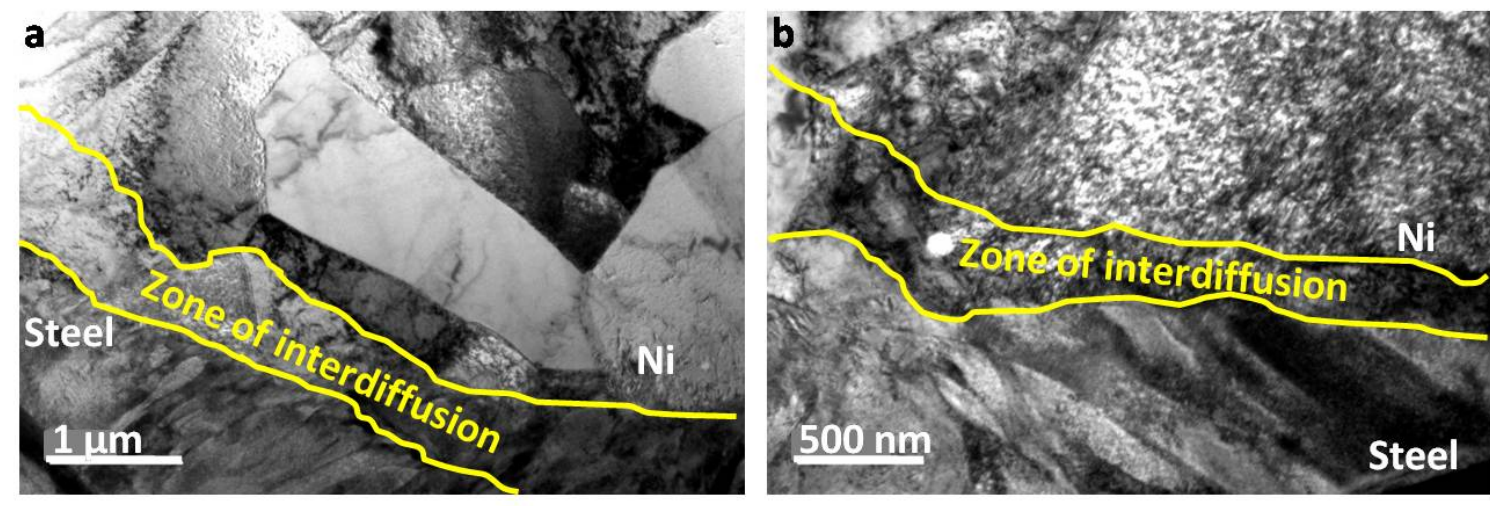
Figure 12: Ni-steel interface in the joint with a $0.2 \mathrm{~mm}$ thick Ni interlayer: a) interfacial zone with Ni grain and b) interfacial zone with a highly dislocated Ni grain (TEM, bright field images). The interdiffusion zone borders are deduced from the EDX analyses.
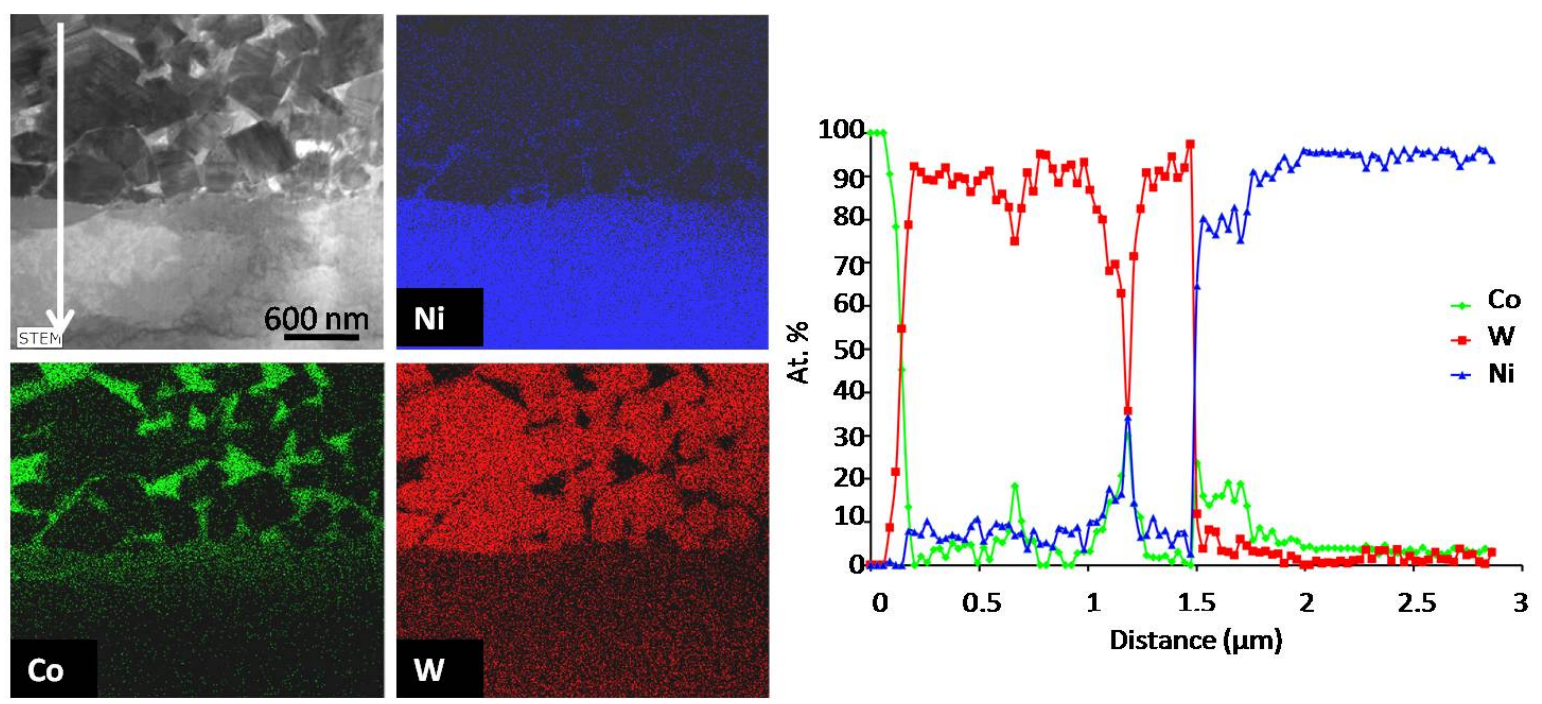

Figure 13: Interdiffusion between $\mathrm{Ni}$ and $\mathrm{Co}$ at the Ni-cermet interface in the joint with the $0.2 \mathrm{~mm}$ thickest Ni interlayer (STEM/EDX). Bright field micrograph, associated Ni Ka, Co $\mathrm{K} \alpha$ and $\mathrm{W} \mathrm{L} \alpha \mathrm{X}$-ray maps and EDX profile along the arrow drawn in the bright field image.

\subsection{Effect of Ni filler thickness on joint microstructure -}

Microstructure at the top surface of the joint - Whatever the joint, its top surface is composed of micrometric grains of low temperature pearlite, acicular ferrite and martensite. The grain size is consistent with the area of the rotated grains visible in figure $6 \mathrm{c}$. This fine grain structure extends over a depth of about $33 \mu \mathrm{m}$ (figure 14). Compared to the $20 \mu \mathrm{m}$ grain size of the base steel (figures $5 \mathrm{a}$ and $\mathrm{b}$ ), the grain refinement originates from the phase transformations caused by the rapid thermal cycle generated by the shoulder friction. Conversely, in accordance with the slower cooling rate, the deeper structure beneath this zone is coarser (figure 14).

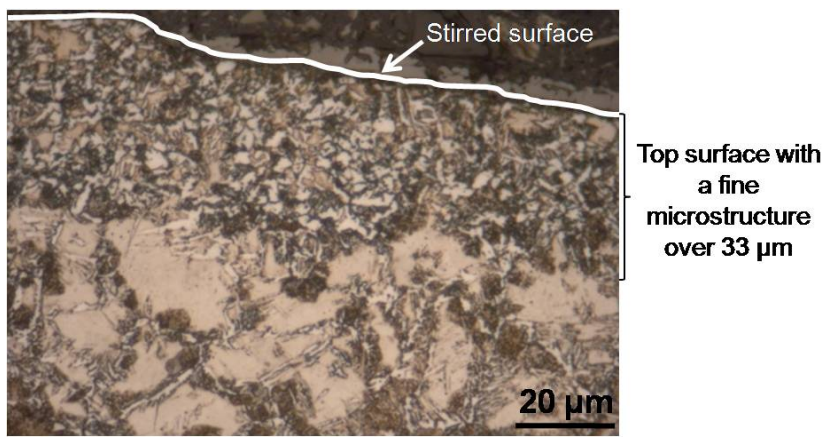

Figure 14: Transverse cross-section of the stirred surface of the Ni-free joint etched with the Leperrra reagent (light microscopy).

\section{Phase transformations -}

Steel microstructure - The Ni-free joint nugget centre presents some retained austenite (see yellow arrows in figure 15a and see figure 16a), Widmanstätten ferrite, some low temperature pearlite (figures 16a and $b$ ) and some martensite (figures $17 \mathrm{a}, \mathrm{b}$ and c). In accordance with the mid carbon content of the steel, martensite is often twinned (see white arrow in figure 17b) 
[3435]. Conversely, for the Ni bearing joints, no Widmanstätten ferrite was detected in the nugget but only low temperature pearlite, retained austenite, martensite (figures $16 \mathrm{c}$ to $16 \mathrm{~h}$ ) and bainite (figure 17d). Between the Ni tongues, light microscopy analyses indeed show the presence of allotriomorphic "necklaces" of low temperature pearlite (see blue arrows in figure $15 \mathrm{~b}$ ) and retained austenite (see yellow arrows in figure 15b) within martensite. The formation of these more quenching phases has very likely to do with the diffusion of the Ni $\gamma$ stabilizing element into the steel. Such an atomic exchange is indeed demonstrated by STEM/EDX (figure 13).

Whatever the joint, the HAZ microstructure on the advancing side consists of low temperature pearlite, retained austenite, bainite and martensite (figure 18a). On the retreating side in the HAZ, some Widmanstätten ferrite decorates the prior austenite grain boundaries which border grains containing martensite and bainite (figure 18b).

Besides peaks due to WC, Co, $\alpha$-ferrite and $\mathrm{Ni}$ (for the Ni bearing joints), the XRD patterns in figure 19 further display the presence of retained austenite whose signal is more clear when the $\mathrm{Ni}$ interlayer is thicker. Moreover, the presence of some $\mathrm{Co}_{\mathrm{x}} \mathrm{W}_{\mathrm{y}} \mathrm{C}_{\mathrm{z}}$ ternary compounds is also detected.
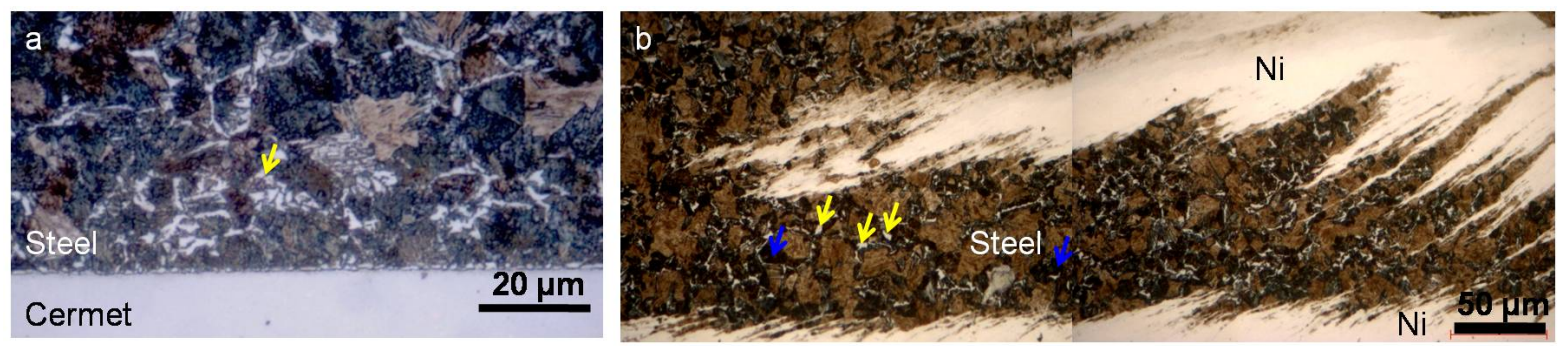

Figure 15: a) Microstructure in the transverse cross-section of the Ni-free joint etched with nital solution. b) Microstructure around the steel-Ni interface and Ni tongues in the transverse cross-section of the steel-cermet joint with a $0.05 \mathrm{~mm}$ thick Ni interlayer. The used Marder $\&$ and Benscoter reagent takes advantage of coloring the retained austenite in white (yellow arrows) (light microscopy).

Ni layer - Some Ni grains with a size of 7-8 $\mu \mathrm{m}$ are detected near the cermet, while their size is smaller near the steel (around 1 to $2 \mu \mathrm{m}$ ) (figures 12a \&and 20). The squared zone in Figure 20 further displays some Ni polygonization near the steel, which suggests that Ni experienced dynamic recovery during FSW. Some Ni grains also exhibit a high density of dislocations (figure 12b) while other ones present some twins of growth (figure 12a). These observations prove that the different zones experienced a distinct mechanical history. 


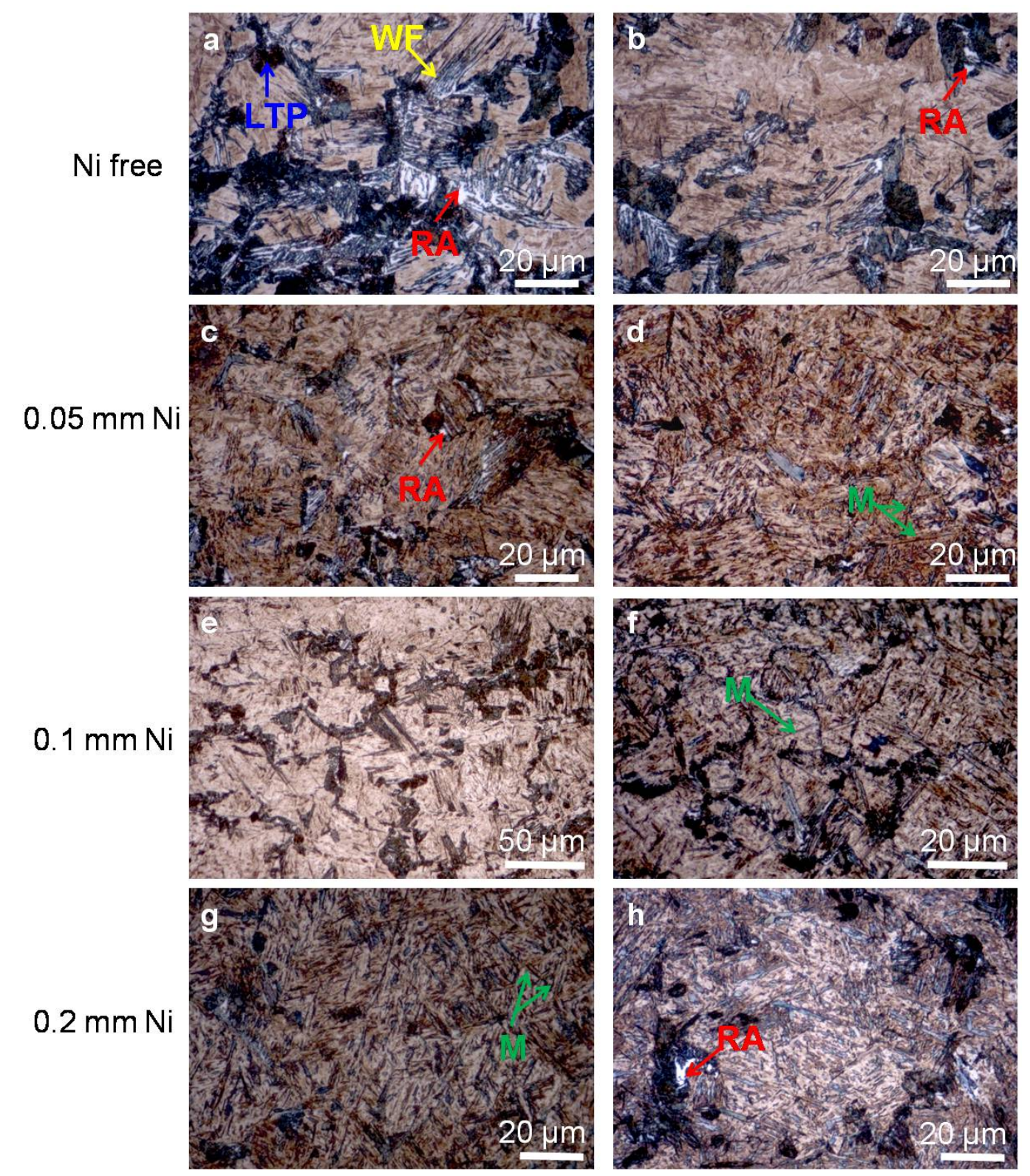

Figure 16: Transverse cross-sections micrographs of the steel nugget centre of the Ni free and $\mathrm{Ni}$ bearing joints etched with nital reagent (light microscopy). $\mathrm{M}$ is the abbreviation for martensite, RA for retained austenite, WF for Widmanstätten ferrite and LTP for low temperature pearlite. 

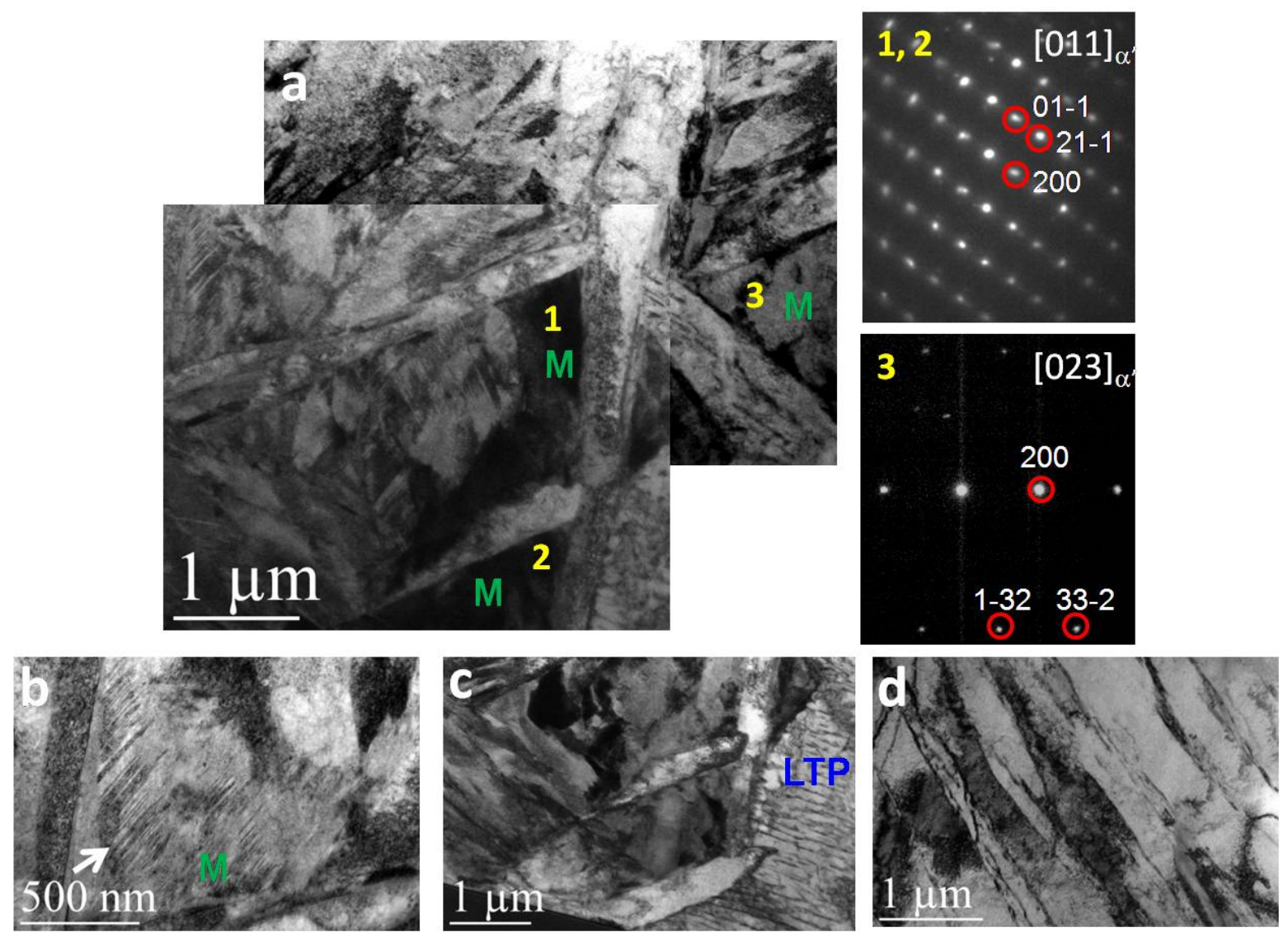

Figure 17: Steel microstructure at a depth of $1 \mathrm{~mm}$ from the joint top surface in the Ni free joint ( $\mathrm{a}, \mathrm{b}$ and $\mathrm{c}$ : bright field images and associated electron diffraction patterns of zones referred as 1,2 and 3 in micrograph a) and in the dissimilar joint with a $0.2 \mathrm{~mm}$ thick Ni filler (d: bright field image) (TEM). M is the abbreviation for martensite and LTP for low temperature pearlite.
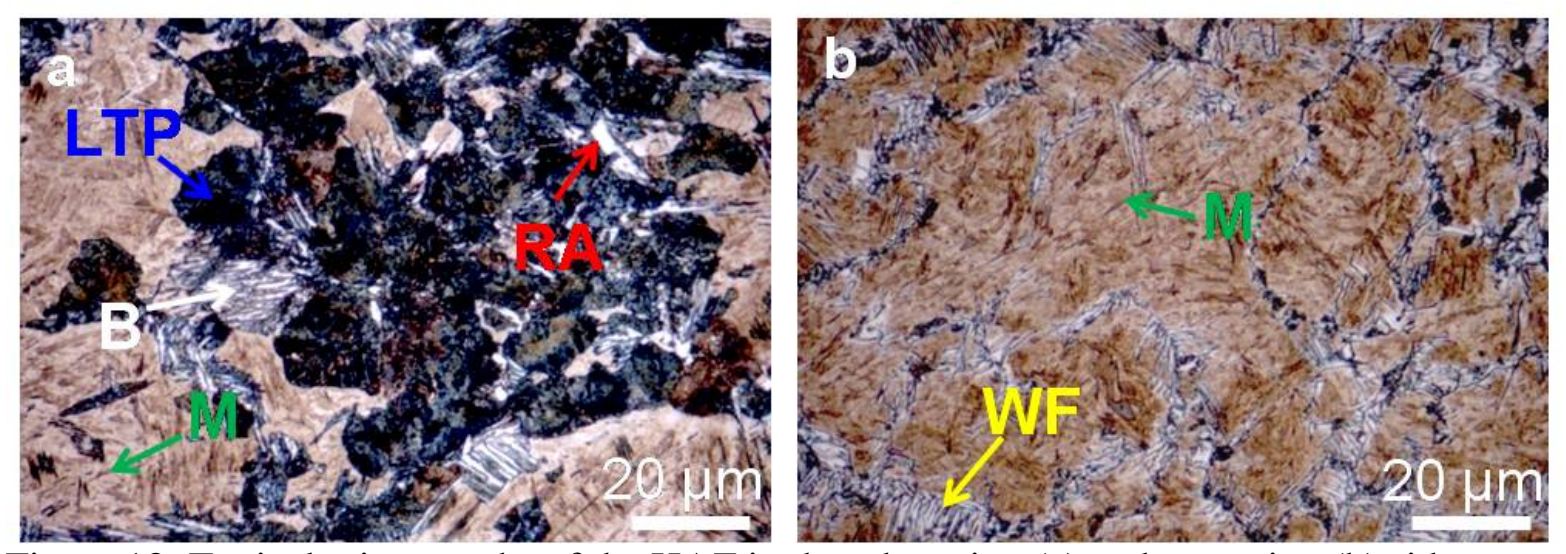

Figure 18: Typical micrographs of the HAZ in the advancing (a) and retreating (b) sides (transverse cross sections, nital etching, light microscopy). RA is the abbreviation for retained austenite, WF for Widmanstätten ferrite, B for bainite, M for martensite and LTP for low temperature pearlite. 


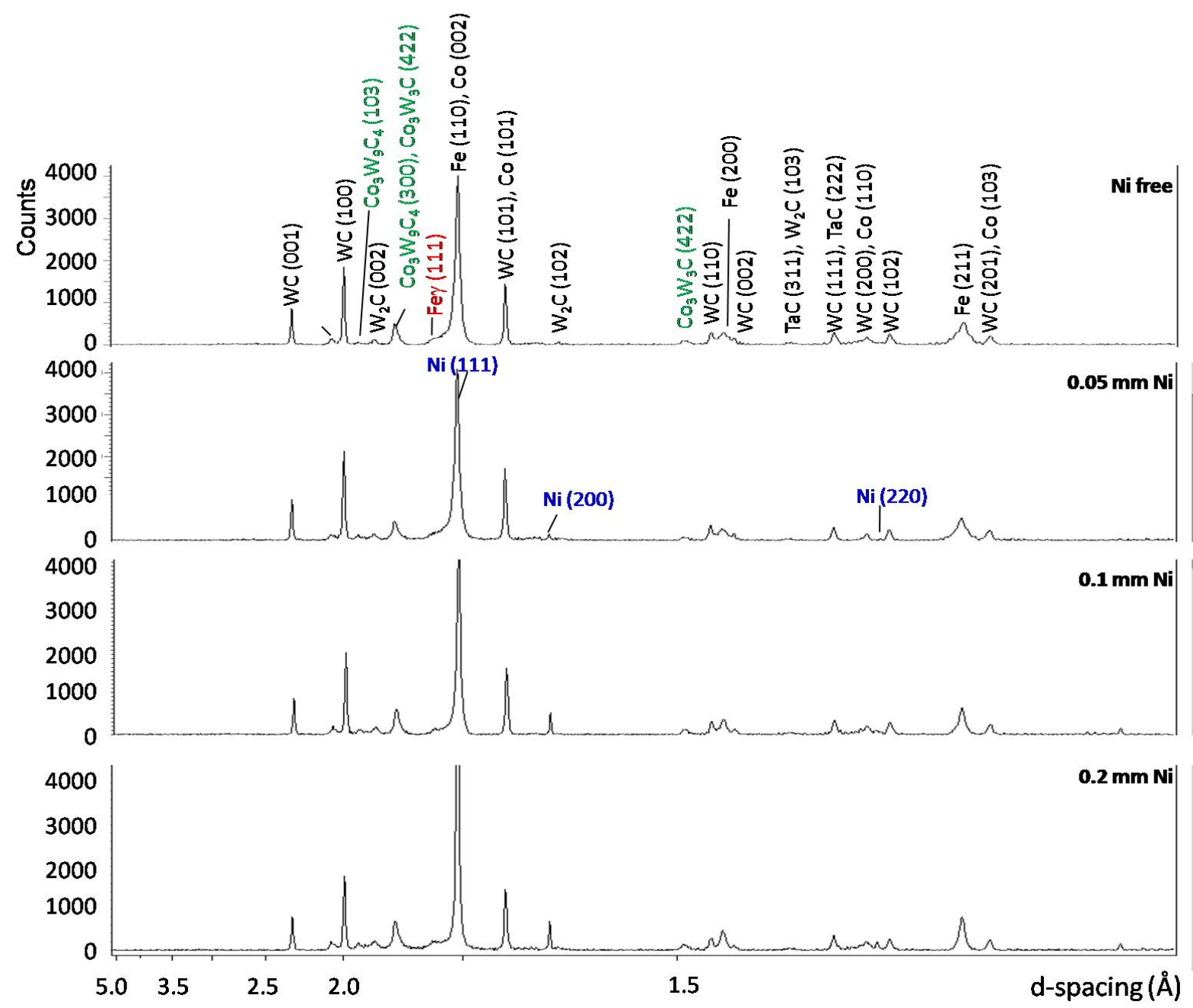

Figure 19: X-ray diffraction patterns of the Ni-free and Ni bearing joints.

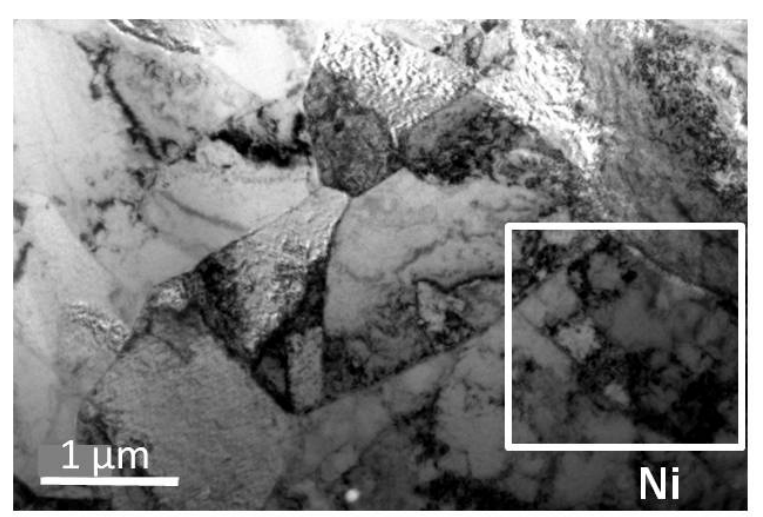

Figure 20: Ni-steel interface in the joint with a $0.2 \mathrm{~mm}$ thick $\mathrm{Ni}$ interlayer: dynamic recovery in $\mathrm{Ni}$.

Interfacial zone - For the Ni-free joint case, Fe originating from the steel has diffused about $2.5 \mu \mathrm{m}$ into the Co binder to form solid solutions with an iron content up to 45 at $\% \mathrm{Fe}$ (figure 21). In the same way, Co has migrated into Fe over a close to $0.5 \mu \mathrm{m}$ depth to form a

(Fe) 20 at.\%Co solid solution (figure 21). 
For the Ni bearing joints, at the steel-Ni interface, some interdiffusion between $\mathrm{Fe}$ and $\mathrm{Ni}$ has occurred over a 1.25 to $1.5 \mu \mathrm{m}$ thick interfacial zone between a steel tongue and a nickel tongue (Figure 22). EDX analyses show that the interfacial area is composed of a solid solution containing 45 at.\% Ni and 50 at.\% Fe (figure 22). At the Ni-cermet interface, even if the FSW tool did not touch this interface, some thermal diffusion has occurred between $\mathrm{Ni}$ and $\mathrm{Co}$ (figure 13). Indeed, Ni has migrated into the Co binder over a distance of about 1.3 $\mu \mathrm{m}$ to form a $(\mathrm{Co})_{35 \mathrm{at} . \% \mathrm{Ni}}$ solid solution. Co also diffused into the Ni over a distance of $1 \mu \mathrm{m}$ and forms a $(\mathrm{Ni})_{20 \text { at. } \% \text { Co }}$ solid solution. .
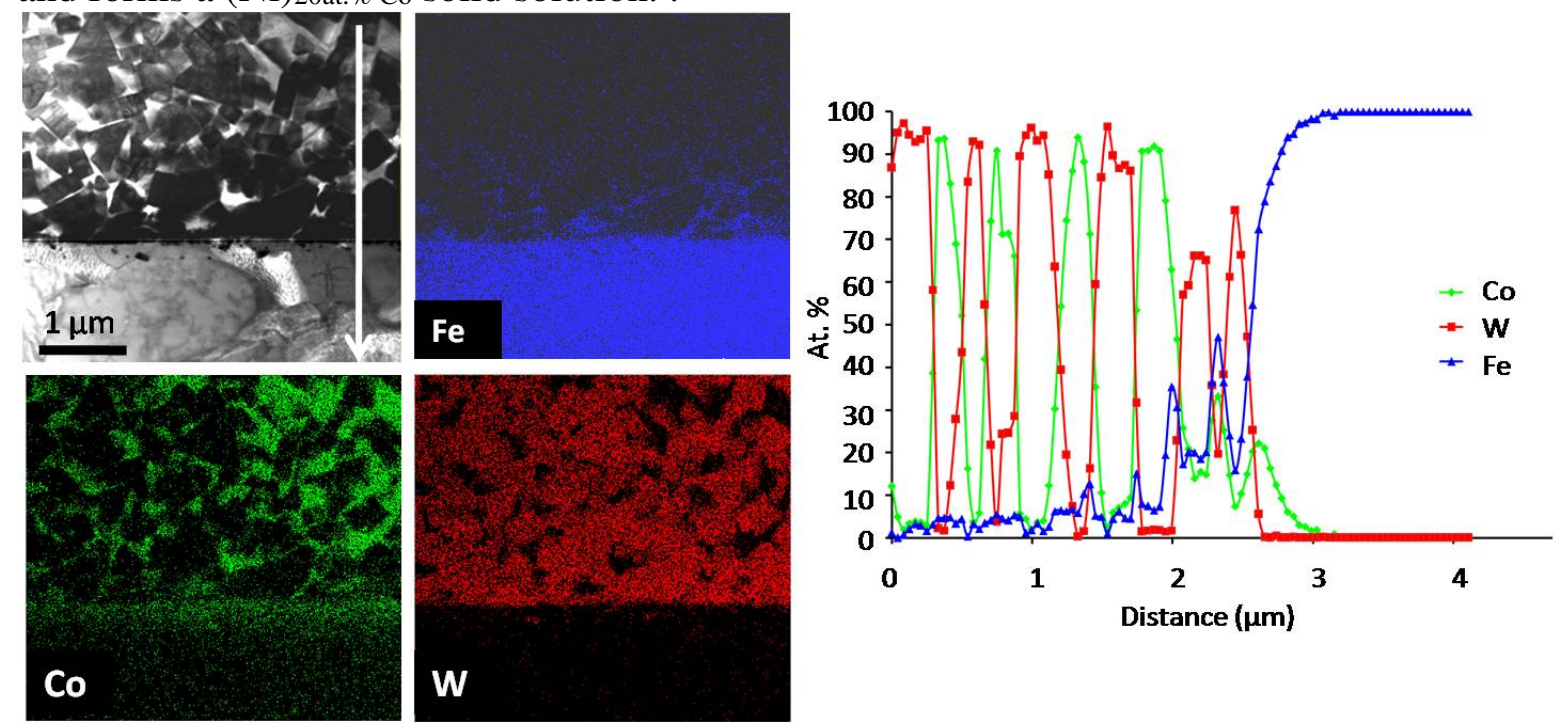

Figure 21: Interdiffusion between $\mathrm{Fe}$ and $\mathrm{Co}$ at the steel-cermet interface in the Ni-free joint (STEM/EDX). Bright field micrograph, associated Fe K $\alpha$, Co K $\alpha$ and $\mathrm{W} \mathrm{L} \alpha \mathrm{X}$-ray maps and EDX profile along the arrow drawn in the bright field image.

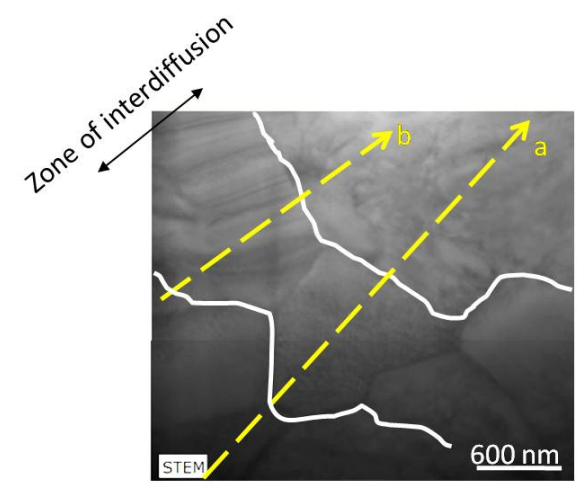

a 100 Zone of interdiffusion

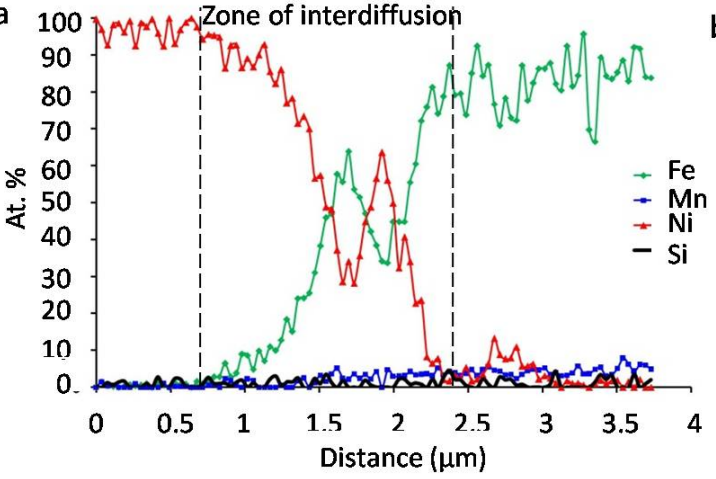

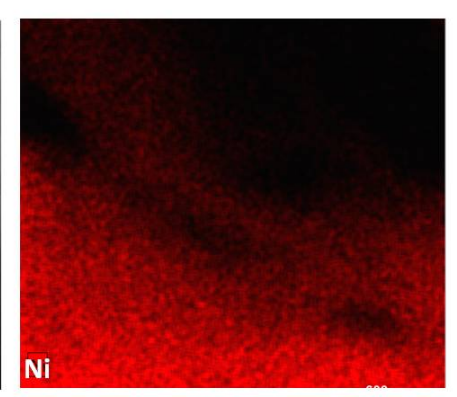
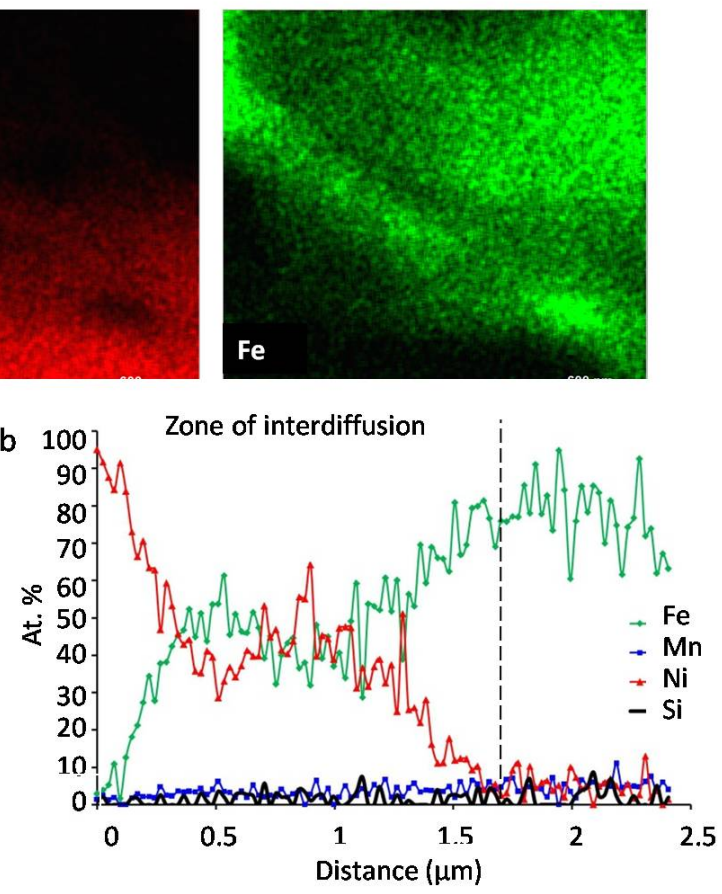
Figure 22: Interdiffusion between $\mathrm{Fe}$ and $\mathrm{Ni}$ at the steel-Ni interface in the joint with the 0.2 $\mathrm{mm}$ thick Ni interlayer (STEM/EDX). Bright field micrograph, associated $\mathrm{Fe} \mathrm{K} \alpha$ and $\mathrm{Ni} \mathrm{K} \alpha$ $\mathrm{X}$-ray maps and EDX profiles along the arrows drawn in the bright field image.

3.6. Effect of the Ni interlayer on the joint mechanical properties - Figure 23 displays the microhardness map of the four joints. It shows that in the presence of $\mathrm{Ni}$, the steel nugget is harder. However, the steel nugget hardness tends to rise with an increase in the Ni interlayer thickness from 0.05 to $0.1 \mathrm{~mm}$, and to decrease when the thickness changes from 0.1 to 0.2 mm.

Concerning the shear-lap tensile properties, the curves for the different joints are depicted in figure 24. Some transient load drops during loading can be noted for all the samples except the Ni $0.2 \mathrm{~mm}$ one. These drops correspond to local crack initiations in the joint. They occur at values of displacement and force which increase with a change in the $\mathrm{Ni}$ thickness from 0 to $0.1 \mathrm{~mm}$. Figure 25 shows the mean and scatter of the results given by the 3 tests performed for each sample. The shear force increases with the addition of a $0.05 \mathrm{~mm}$ thick Ni interlayer while it decreases with a further increase in the Ni thickness (figure 25a). With regard to the displacement, it tends to increase with the Ni thickness (figure 25a).

Similarly, the fracture energy of the joint tends to rise with the Ni thickness (figure 25b). It is doubled for a joint with a $0.2 \mathrm{~mm}$ thick Ni layer compared to the Ni free weld. In addition, the joint fracture surfaces are depicted in figure 26 . Whatever the joint, fracture initiation occurs at the sample surface, very likely because of the presence of machining defects. For the Ni free joint, failure initiates at the steel-cermet interface and propagates within the cermet; for the joint with a $0.05 \mathrm{~mm}$ thick Ni layer, fracture takes place in the cermet. For joints with a 0.1 or $0.2 \mathrm{~mm}$ thick $\mathrm{Ni}$ layer, the fracture initiates in the cermet and propagates by shear into the Ni layer. In the latter case, the shear strength is consistent with the shear strength of pure Ni [2930].
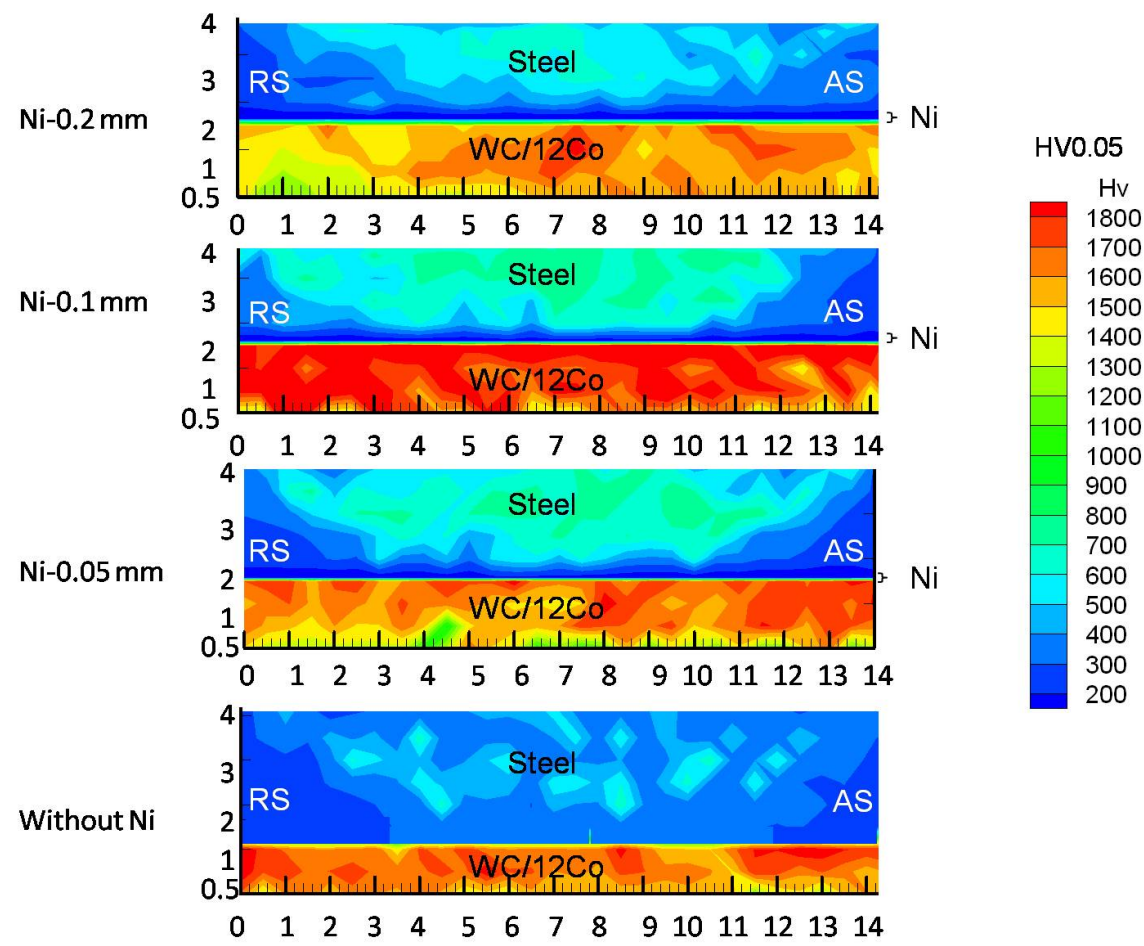

Figure 23: Microhardness maps of the transverse cross-sections of the different joints (plane $\mathrm{X}-\mathrm{Y}$ ). (The units for the $\mathrm{X}$ and $\mathrm{Y}$ axes are in $\mathrm{mm}$ ). 


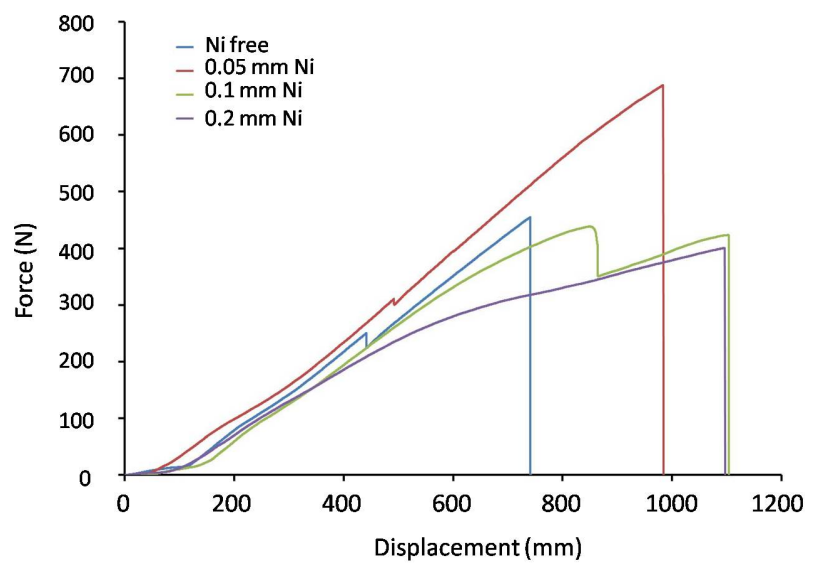

Figure 24: Typical shear-lap tensile curves for the Ni free and Ni bearing joints.
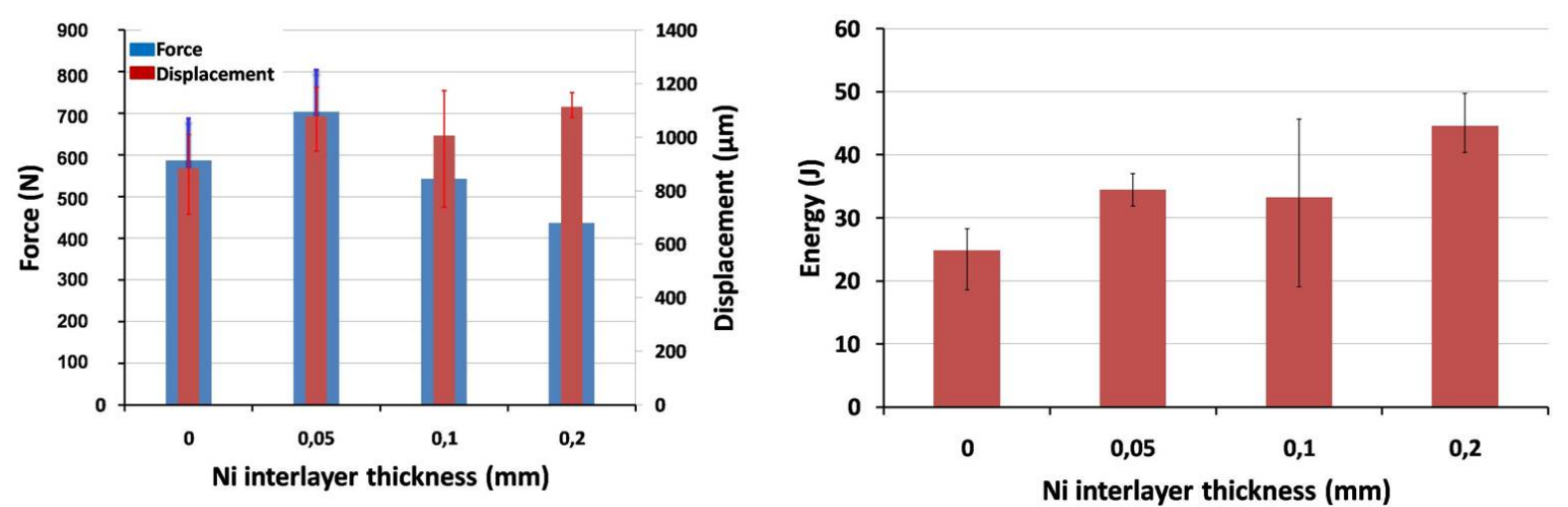

Figure 25: a) Maximum shear-lap force and displacement vs. the Ni layer thickness and b) energy consumed for the total fracture of the various joints. 

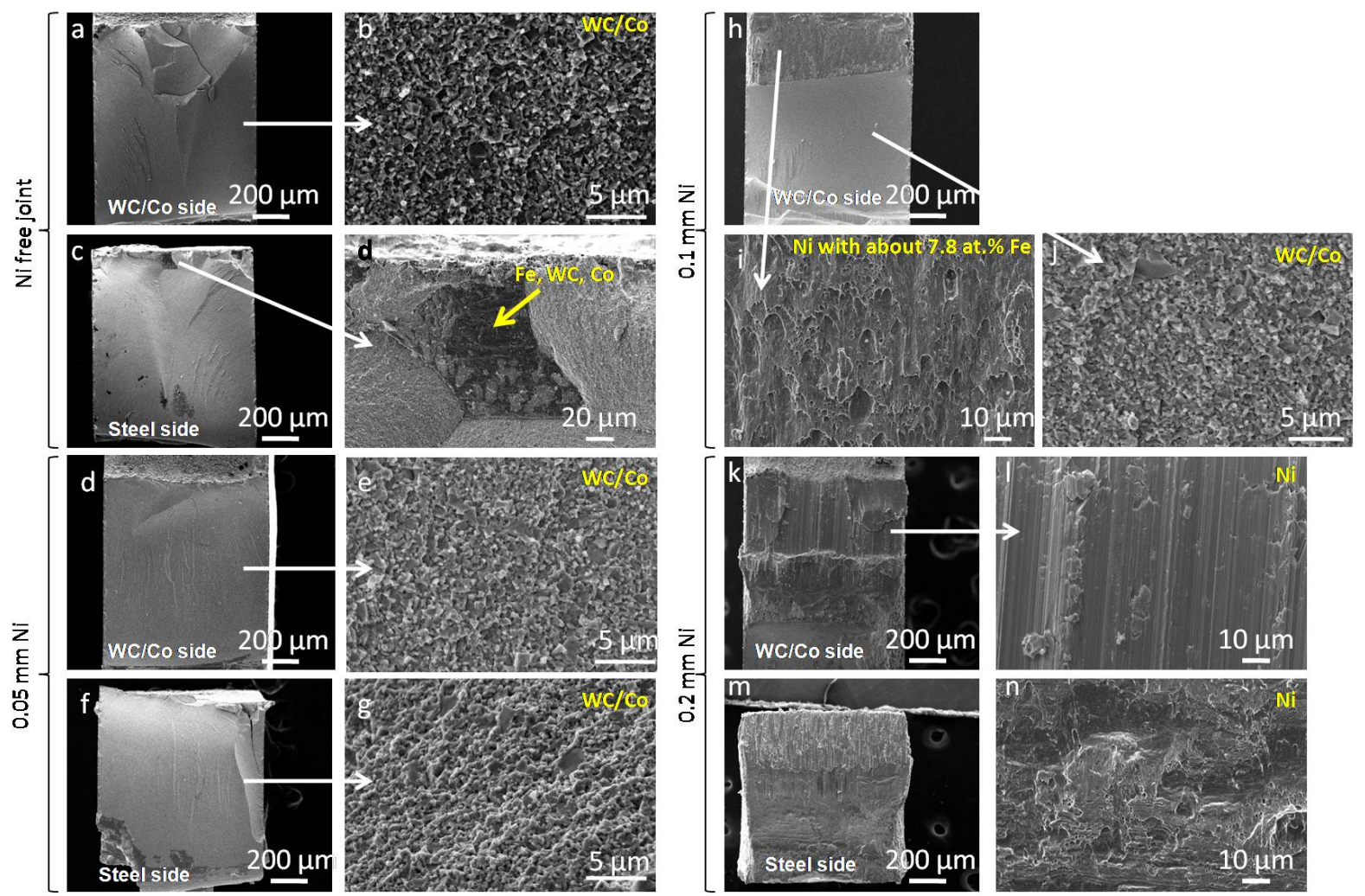

Figure 26: Fracture surfaces of the joints (SE/SEM micrographs).

\section{Discussion}

Material flow- According to the open literature, the formation of onion rings using a smooth pin is controversial. For instance, some studies emphasize the absence of onion rings using a smooth truncated pin [3536] contrary to other ones [36-3737-38]. However, in a general way, material flow during FSW varies according to the respective nature of the materials and tool, to the plates thickness [3233], to the lap or butt configuration in case of the hybrid materials, to the tool shape and dimensions and to the process parameters. Besides material flow is difficult to visualize all the more that it is studied neither in three dimensions nor in situ in the present case and that phase transformations can hide the deformation paths, particularly in steels.

In the present study, the penetration of the smooth conical truncated tool entails material deep drawing at its close contact. This downflow is followed by centripetal displacement beneath the pin tip. Due to the constant volume of the material, die effect of the interface and tool rotation, there is a helical material upflow and extrusion due to the tool advance. This upflowing material is in close contact with the central downflow. The upflow is consistent with the penetration of the harder material into the softer one. $\mathrm{Ni}$ is in fact expected to be harder than steel according to the chemical composition of the hooks. However, it is difficult to estimate the difference in the mechanical strengths of both materials as realistic constitutive laws are lacking for the SC45 steel in the FSW conditions (high temperature close to $1000^{\circ} \mathrm{C}$, strain up to 130, strain rate of about $650 \mathrm{~s}^{-1}$ [38-4839-49]).

The onion formation arises from the upflow of both steel and Ni. For Ni, this displacement is expected to be easier the thicker the layer is. The complex multilayered microstructure and uneven spacing of the onion rings very likely arise from the adhesive tool wear.

Phase transformations and retained austenite - According to previous estimations in thermodynamical equilibrium [24], Ac1 and Ac3 are, respectively, $722^{\circ} \mathrm{C}$ and $774^{\circ} \mathrm{C}$ while 
Ms is greater than $329^{\circ} \mathrm{C}$. Ac1 and Ac3 are lower than the $988^{\circ} \mathrm{C}$ and $916^{\circ} \mathrm{C}$ peak temperatures recorded in the steel HAZ on the AS for the Ni free joint and for the joint with a $0.2 \mathrm{~mm} \mathrm{Ni}$ thick interlayer, respectively. The latter temperatures are actually lower than the temperatures reached in the steel nugget. It indicates that both the nugget and HAZ have experienced more or less complete austenitization. According to the cooling rate (see thermal profiles in figure 4), to the local chemical composition and to the thermomechanical history experienced by the different zones, various low temperature phase transformations (figures $15,16,17,18)$, leading to Widmanstätten ferrite, low temperature pearlite, bainite and martensite occur during cooling. Some retained austenite is also detected by microscopy and XRD (figures 16, 18, 19). XRD analyses suggest that an increase in the Ni thickness leads to a greater amount of retained austenite (figure 19). Ni and Co are gamma stabilizing elements [4950] which are able to promote the formation of retained austenite.

Interfacial zone - With regard to the Co-Fe interface, diffusion led to the formation of $(\mathrm{Co})_{45 a t . \% \mathrm{Fe}}$ and $(\mathrm{Fe})_{20 \text { at. } \% \mathrm{Co}}$ solid solutions in the Ni-free joints. Since at $500^{\circ} \mathrm{C}$, the solubility of $\mathrm{Fe}(\mathrm{Co})$ in $\mathrm{Co}(\mathrm{Fe})$ amounts to $9(75)$ at.\% [2930], FSW gave rise to a Co based solid solution oversaturated in $\mathrm{Fe}$.

In the same way at the Co-Ni interfacial zone in the joint with the $0.2 \mathrm{~mm}$ thick $\mathrm{Ni}$ interlayer, diffusion led to the formation of $(\mathrm{Co})_{35 \text { at.\% }} \mathrm{Ni}$ and $(\mathrm{Ni})_{25 \text { at.\% }}$ Co solid solutions. However, the solubility of $\mathrm{Ni}(\mathrm{Co})$ in $\mathrm{Co}(\mathrm{Ni})$ amounts to $12(82)$ at.\% at $300^{\circ} \mathrm{C}$ [2930], which indicates the formation of a Co based solid solution oversaturated in Ni. The formation of Co based oversaturated solid solutions agrees with the deformation of the material below the pin. The generation of a high density of lattice defects during metal working [4950] has very likely promoted a significant diffusion of atoms of $\mathrm{Fe}$ in the case of the Ni-free joint and of $\mathrm{Ni}$ in the case of $\mathrm{Ni}$ bearing joints into the Co binder of the cermet in spite of the short welding time of only a few seconds (figure 4).

Concerning the $\mathrm{Fe}-\mathrm{Ni}$ interface in the $\mathrm{Ni}$ bearing joint, a binary solid solution containing 45 at. $\% \mathrm{Ni}$ is formed whereas the solubility of $\mathrm{Ni}$ in Fe is very low and below 3 at. $\%$ at $0^{\circ} \mathrm{C}$

[2930]. The present Fe-Ni solid solution is thus and once again oversaturated in $\mathrm{Ni}$.

With regard to diffusion, the measured distances are reported in table 3 and compared with those calculated by taking account of the single effect of temperature and neglecting the concomitant and important effect of the lattice defects [5051]. The calculations were done using the diffusion coefficients found in the literature for a holding time of 3 seconds at the welding temperature. Such a duration is deduced from the thermal cycles. The welding temperature is expected to be close to $1000^{\circ} \mathrm{C}$ since the nugget temperature is greater than that recorded on the steel AS (figure 4). Under equilibrium conditions, the diffusion coefficient of $\mathrm{Fe}$ into Co amounts to $4.410^{-12} \mathrm{~cm}^{2} / \mathrm{s}$ at $1000^{\circ} \mathrm{C} v s .6 .410^{-12} \mathrm{~cm}^{2} / \mathrm{s}$ at $1136^{\circ} \mathrm{C}$ for Co into $\mathrm{Fe}$; the diffusion coefficient of Fe into $\mathrm{Ni}$ amounts to $9.2210^{-12} \mathrm{~cm}^{2} / \mathrm{s}$ at $1000^{\circ} \mathrm{C}$ vs. $2.3710^{-12} \mathrm{~cm}^{2} / \mathrm{s}$ for $\mathrm{Ni}$ into $\mathrm{Fe}$; the diffusion coefficient of Co into $\mathrm{Ni}$ amounts to $5.1010^{-}$ $12 \mathrm{~cm}^{2} / \mathrm{s}$ at $1000^{\circ} \mathrm{C}$ vs. $3.0510^{-12} \mathrm{~cm}^{2} / \mathrm{s}$ for $\mathrm{Ni}$ into Co [2930]. Table 3 shows that the diffusion layers are thicker than those calculated under equilibrium conditions. $\mathrm{Fe}$ and $\mathrm{Ni}$ diffuse in $\mathrm{Co}$, $\mathrm{Fe}$ in $\mathrm{Ni}$ and $\mathrm{Ni}$ in $\mathrm{Fe}$, over distances which are greater than those over which Co diffuses into $\mathrm{Fe}$ and $\mathrm{Ni}$ (table 3). These results are consistent since the volumes of steel and $\mathrm{Ni}$ deformed by the tool are larger than the cermet one. Actually, the heat stored in steel is larger than that in cermet while the heat stored in $\mathrm{Ni}$ is intermediate. Indeed, according to the densities, thermal conductivities, and specific heat capacities of cermet, steel and $\mathrm{Ni}$ (table 1), the cermet dissipates more heat and cools more rapidly than $\mathrm{Ni}$ which dissipates more heat and cools more rapidly than steel.

Table 3: Diffusion distances of Co, Fe and Ni. 


\begin{tabular}{|c|c|c|c|c|}
\hline Sample & Diffusion & $\begin{array}{c}\text { Actual thickness of } \\
\text { the interdiffusion } \\
\text { layer }(\mu \mathrm{m}) \\
\text { [present study] }\end{array}$ & $\begin{array}{c}\text { Theoretical } \\
\text { distance of } \\
\text { thermal diffusion } \\
(\mu \mathrm{m})\end{array}$ & $\begin{array}{c}\text { Actual } \\
\text { measurement over } \\
\text { thermal estimate }\end{array}$ \\
\hline \multirow{2}{*}{$\begin{array}{c}\text { Ni free } \\
\text { joint }\end{array}$} & of Fe into Co & 2.5 & $3.7 \times 10^{-2}$ & 67.5 \\
\cline { 2 - 5 } & of Co into Fe & 0.5 & $4.4 \times 10^{-2}$ & 11.5 \\
\hline \multirow{2}{*}{$\begin{array}{c}\text { Joint with } \\
\text { a } 0.2 \mathrm{~mm} \\
\text { thick } \mathrm{Ni} \\
\text { interlayer }\end{array}$} & of Fe into $\mathrm{Ni}$ & 1.25 to 1.5 & $5.3 \times 10^{-2}$ & 28.3 \\
\cline { 2 - 5 } & of Ni into Fe & 1.25 to 1.5 & $2.7 \times 10^{-2}$ & 55.5 \\
\cline { 2 - 5 } & of Co into Ni & 1 & $3.9 \times 10^{-2}$ & 25.6 \\
\hline \multirow{2}{*}{} & of into $\mathrm{Co}$ & 1.3 & $3.0 \times 10^{-2}$ & 43.3 \\
\hline
\end{tabular}

Coefficient of Thermal Expansion - Because of its excellent plasticity [5], and as proven in the literature [14], the insertion of $\mathrm{Ni}$ should have solved the problem of the CTE gap between steel and cermet. In addition, the present formation of a Fe-45at.\%Ni solid solution with a composition close to that of the Invar alloy can be an advantage. Invar alloys present the advantage of having a coefficient of thermal expansion around $8.910^{-6}{ }^{\circ} \mathrm{C}^{-1}$ over the $[20$ $500^{\circ} \mathrm{C}$ ] temperature range [5152], which is intermediate between those of SC45 steel and cermet (Table 1) and could contribute to limit the thermal stresses at the joint interface.

Effect of the Ni interlayer on mechanical properties - The formation of solid solutions promoted by the high solubility of $\mathrm{Ni}$ in both $\mathrm{Co}$ and Fe [2930] as well as the Ni presence, which avoids the formation of the brittle $\eta$ phase at the steel-cermet interface, warrant suitable interfacial joint strength and ductility. Indeed fracture occurs in the cermet base material instead of the joint interface. The plastic deformation of $\mathrm{Ni}$ at the steel-cermet interface improves the joint ductility, despite a small increase in the hardness difference between steel and cermet (figure 25a). In addition, the mechanical resistance of the Ni bearing joints is far greater than those of most of the joints with an interlayer reported in the literature and developed by brazing [2,4,5,8], high frequency induction brazing [9], TIG brazing [21], diffusion welding $[\mathbf{9 - 1 1 , 1 6 , 1 7 , 1 8 , 1 9 ]}$ or plasma activated sintering [20]. Only 1 paper mentioned a higher mechanical strength for joints developed by laser welding [14]. The present values of shear strength and toughness must be questioned since fracture was promoted by the stress concentration effect of the surface defects formed during the machining of the shear tensile samples. The random location of these stress raisers, which are not perfectly placed in the joint plane, however prevents us from comparing the bond strength of the various samples. The usefulness of notch tensile testing is indeed well known so as to detect embrittlement phenomena [5253].

At last, the joint ductility is not very high but it cannot be compared to those of the metal cermet joints developed in previous works since they do not mention it. Nevertheless the solid solutions developed at the joint interface are less detrimental than continuous thick interfacial intermetallic compounds regarding the ductility of the joints but their thickness seems to be too limited.

Further investigations dealing for instance with the microstructure stability, toughness, thermal fatigue, thermal shock resistance, wear and corrosion resistance under realistic solicitations are however necessary in order to establish the reliability of FSW joints in use. Forging die inserts and high speed milling tools with increased life time are examples of possible applications.

\section{Conclusions}


- The present study proves that the addition of a Ni interlayer improves the feasibility of welding WC-12Co cermet to SC45 steel by friction stir lap welding. Actually, during shear lap tensile tests, fracture initiates at the steel-cermet interface and propagates in the cermet for the $\mathrm{Ni}$ free joint; while it occurs in the base materials for the $\mathrm{Ni}$ bearing joints. The Ni layer also gives rise to the formation of a solid solution able to confer a graded coefficient of thermal expansion to the joint.

- The use of dissimilar materials and especially of a Ni interlayer enables visualization of the material flow in the stirred zone. It is worthy to note the presence of onion rings in spite of the use of a smooth conical truncated tool.

- The microstructure of the joint nuggets consists of Widmanstätten ferrite, low temperature pearlite, bainite, martensite and retained austenite. Some interdiffusion is noticed at the steel-cermet, steel-Ni and Ni-cermet interfaces. The formation of supersaturated Co based solid solutions in Fe or in $\mathrm{Ni}$ is noted. A solid solution with a chemical composition close to that of Invar is also present.

- The increase in the Ni interlayer thickness leads

- to a more pronounced $\mathrm{Si}_{3} \mathrm{~N}_{4}$ tool wear, and

- to a greater amount of retained austenite in the nugget.

\section{References}

[1] Lee WB, Kwon BD, Jung SB. Effect of bonding time on joint properties of vacuum brazed WC-Co hard metal / carbon steel using stacked $\mathrm{Cu}$ and Ni alloy as insert metal. Mater. Sci. Technol. 2004;20(11):1474-1478.

[2] Chiu LH, Wang HF, Huang CP, Hsu CT, Chen TC. Effect of brazing temperature on the microstructure and property of vacuum brazed WC-Co and carbon steel joint. Multi-Funct. Mater. Struct. 2008;47-50:682-685.

[3] Nowacki J, Kawiak M. Microstructure and characteristics of high dimension brazed joints of cermets and steel. J. Achiev. Mater. Manuf. Engin. 2009;37(2):448-457.

[4] Chen H, Feng K, Wei S, Xiong J, Guo Z, Wang H. Microstructure and properties of WC-Co/3Cr13 joints brazed using Ni electroplated interlayer. Int. J. Refract. Met. Hard Mater. 2012;33:70-74.

[5] Chen H, Feng K, Xiong J, Guo Z, Characterization and stress relaxation of the functionally graded WC$\mathrm{Co} / \mathrm{Ni}$ component/stainless steel joint. J. All. Compnds. 2013;557:18-22.

[6] Kaïwa K, Yaoita S, Sasaki T, Watanabe T. Effects of Ni and Co additions to filler metal on Ag-brazed joints of cemented carbide and martensitic stainless steel. Adv. Mater. Res. 2014;922:322-327.

[7] Uzkut M, Sinan Köksal N, Sadik Ünlü B. The determination of element diffusion in connecting SAE 1040/WC material by brazing. J. Mater. Process. Technol. 2005;169:409-413.

[8] Lee WB, Kwon BD, Jung SB. Effects of $\mathrm{Cr}_{3} \mathrm{C}_{2}$ on the microstructure and mechanical properties of the brazed joints between WC-Co and carbon steel. Int. J. Refract. Met. Hard Mater. 2006;24:215-221.

[9] Jiang C, Chen H, Wang Q, Li Y. Effect of brazing temperature and holding time on joint properties of induction brazed WC-Co/carbon steel using Ag-based alloy. J. Mater. Process. Technol. 2016;229:562-569.

[10] Xu PQ, Zhao XJ, Yang DX, Yao S. Study on the filler metal (Ni-Fe-C) during GTAW of WC-30Co to 45\% C carbon steel, J. Mater. Sci. 2005;40:6559-6564.

[11] Xu P, Yang D, Zhao X, Chen C, Wang Q. Ni-Fe-C alloy effect on $\eta$ - phases formed during TIG welding of YG30 with S45C. Rare Metals and Cemented Carbides 2003;312:18-23.

[12] Barbatti C, Garcia J, Liedl G, Pyzalla A. Joining of cemented carbides to steel by laser beam welding, Materialwiss. Werkstofftech. 2007;38(11):907-914. 
[13] Costa AP, Quintino L, Greitmann M. Laser beam welding hard metals to steel. J. Mater. Process. Technol. 2003;141:163-173.

[14] Yu XY, Zhou DR, Yao DJ, Lu FG, Xu PQ. Fiber laser welding of WC-Co to carbon steel using Fe-Ni Invar as interlayer. Int. J. Refract. Met. Hard Mater. 2016;56:76-86.

[15] Chen G, Zhang B, Wu Z, Shu X, Feng J. Microstructure transformation and crack sensitivity of WCCo/steel joint welded by electron beam. Vacuum 2017;139:26-32.

[16] Barrena MI, Gomez de Salazar JM, Matesanz L. Ni-Cu alloy for diffusion bonding cermet/steel in air. Mater. Letters 2009;63:2142-2145.

[17] Barrena MI, Gomez de Salazar JM, Matesanz L. Interfacial microstructure and mechanical strength of WC-Co/90MnCrV8 cold work tool steel diffusion bonded joint with $\mathrm{Cu} / \mathrm{Ni}$ electroplated interlayer. Mater. Design 2010;31:3389-3394.

[18] Klaasen H, Kübarsepp J, Laansoo A, Viljus M. Reliability of dual compounds "carbide composite + steel” produced by diffusion welding. Int. J. Refract. Met. Hard Mater. 2010;28:580-586.

[19] Feng K, Chen H, Xiong J, Guo Z. Investigation on diffusion bonding of functionally graded WC-Co/Ni composite and stainless steel. Mater. Design 2013;46:622-626.

[20] Guo Y, Wang Y, Gao B, Shi Z, Yuan Z. Rapid diffusion bonding of WC-Co cemented carbide to 40Cr steel with $\mathrm{Ni}$ interlayer: Effect of surface roughness and interlayer thickness. Ceramics Intern. 2016;42(15):16729-16737.

[21] Cheniti B, Miroud D, Badji R, Allou D, Csanadi T, Fides M, Hvizdos P. Effect of brazing current on microstructure and mechanical behavior of WC-Co/AISI 1020 steel TIG brazed joint. Int. J. Refract. Met. Hard Mater. 2017;64:210-218.

[22] Xu PQ. Dissimilar welding of WC-Co cemented carbide to $\mathrm{Ni}_{42} \mathrm{Fe}_{50.9} \mathrm{C}_{0.6} \mathrm{Mn}_{3.5} \mathrm{Nb}_{3}$ invar alloy by lasertungsten inert gas hybrid welding, Mater. Design 2011;32:229-237.

[23] Morisada Y, Fujii H, Mizuno T, Abe G, Nagaoka T, Fukusumi M. Modification of thermally sprayed cemented carbide layer by friction stir processing. Surf. Coat. Technol. 2010;204(15):2459-2464.

[24] Avettand-Fènoël MN, Nagaoka T, Fujii H, Taillard R. Characterization of WC/12Co cermet -steel dissimilar friction stir welds. J. Manuf. Proc. 2018;31:139-155.

[25] Hong S, Wu Y, Gao W, Zhang J, Zheng Y, Zheng Y. Slurry erosion-corrosion resistance and microbial corrosion electrochemical characteristics of $\mathrm{HVOF}$ sprayed $\mathrm{WC}-10 \mathrm{Co}-4 \mathrm{Cr}$ coating for offshore hydraulic machinery. Int. J. Refract. Met. Hard. Mater. 2018;74:7-13.

[2526] Ji GC, Wang HT, Chen X, Bai XB, Dong ZX, Yang FG. Characterization of cold-sprayed multimodal WC-12Co coating, Surf. and Coat. Technol. 2013;235:536-543.

[2627] Dosta S, Couto M, Guilemany JM. Cold spray deposition of a WC-25Co cermet onto Al7075-T6 and carbon steel substrates. Acta Mater. 2013;61:643-652.

[2728] Suganuma K. Joining ceramics and metals, Handbook of advanced ceramics, Chapter 10.1, Elsevier 2013:775-788.

[2829] Zhang Y, Feng D, He ZH, Chen XC. Progress in joining ceramics to metals. J. iron steel res. intern. 2006;13(2):01-05.

[2930] Smithells Metal Reference Book, seventh edition, Eds E.A. Brandes, G.B. Brook, Oxford; 1992.

[3031] www.matweb.com 
[3132] Klocke F, Manufacturing Processes - Part 1 - Cutting, RWTH edition - Aachen University, Springer, Berlin 2011:118.

[3233] Avettand-Fènoël MN, Taillard R, Laye J, Odièvre T. Experimental investigation of three-dimensional (3-D) material flow pattern in thick dissimilar 2050 friction-stir welds. Met. Mat. Trans. A 2014;45:563-578.

[3334] Heideman R, Johnson C, Kou S. Metallurgical analysis of Al/Cu friction stir spot welding. Sci.Technol. Weld. Join. 2010;15:597-604.

[3435] Wayman CM, Physical Metallurgy, tome 2, chapter 15, Eds. RW Cahn, P. Haasen North-Holland Physics Publishing, Elsevier Science Publishers, Amsterdam 1983, p. 1031-1074.

[3536] Zhao YH, Lin S, Qu F, Wu L. Influence of pin geometry on material flow in friction stir welding process. Mater. Sci. Technol. 2006;22(1):45-50.

[3637] Lorrain O, Favier V, Zahrouni H, Lawrjaniec D. Understanding the material flow path of friction stir welding process using threaded tools. J. Mater. Process. Techn. 2010;210(4):603-609.

[3738] Morisada Y, Fujii H, Nagaoka T, Nogi K, Fukusumi M. Composites : part A 2007;38:2097-2101.

[3839] Mishra RS, Ma ZY. Friction Stir Welding and Processing. Mater. Sci. Eng. R 2005;50:1-78.

[3940] Nandan R, DebRoy T, Bhadeshia HKDH. Recent advances in friction stir welding - process, weldment, structure and properties. Prog. Mater. Sci. 2008;53:980-1023.

[4041] Arora A, Zhang Z, De A, DebRoy T. Strain and strain rates during friction stir welding. Scripta Mater. 2009;61:863-866.

[4142] Buffa G, Hua J, Shivpuri R, Fratini L. A continuum based fem model for friction stir welding - model development. Mater. Sci. Eng. A 2006;419:381-388.

[4243] Masaki K, Sato YS, Maeda M, Kokawa H. Experimental simulation of recrystallized microstructure in friction stir welded Al alloy using a plane strain compression test. Scripta Mater. 2008;58:355-360.

[4344] Jata KV, Semiatin SL. Continuous dynamic recrystallization during friction stir welding of high strength aluminum alloys. Scripta Mater. 2000;43:743-749.

[4445] Frigaard $\varnothing$, Grong $\varnothing$, Midling OT. A process model for friction stir welding of age hardening aluminum alloys, Metall. Mater. Trans. A 2001;32:1189-1200.

[4546] Gerlich A, Avramovic-Cingara G, North TH. Stir zone microstructure and strain rate during Al 7075-T6 friciton stir spot welding. Metall. Mater. Trans. A 2006;37:2773-2786.

[4647] Heurtier P, Desrayaud C, Montheillet F. A thermomechanical analysis of the friction stir welding process. Mater. Sci. Forum 2002;396-402:1537-1542.

[4748] Schmidt H, Hattel J. A local model for the thermomechanical conditions in friction stir welding, Modell. Simul. Mater. Sci. Eng. A 2005;13:77-93.

[4849] Buffa G, Hua J, Shivpuri R, Fratini L. A continuum based fem model for friction stir welding model development, Mater. Sci. Eng. A 2006;419:389-396.

[4950] Lacombe P, Baroux B, Béranger G, eds, Les aciers inoxydables, Editions de Physique, Les Ulis, 1990.

[5051] Militzer M, Sun WP, Jonas JJ. Modeling the effect of deformation-induced vacancies on segregation and precipitation. Acta Metall. Mater. 1994;42:133-141.

[5152] http://www.aperam.com/alloysandspecialities/fileadmin/pdf/datasheets_uk/Documentation_web__Invar_-_Francais_25_juillet_2011.pdf 
[5253] Dieter GE, Mechanical Metallurgy, Mc Graw -Hill Kogakusha Ltd, 1961. 


\section{Figure captions}

Figure 1: Lap FSW process settings for Ni free and Ni bearing joints. AS and RS are the abbreviations for the advancing and retreating sides, respectively.

Figure 2: Thermocouple locations in the $(\mathrm{X}, \mathrm{Y})$ transverse cross section of the joint.

Figure 3: Shear lap tensile test setting.

Figure 4: Thermal cycles of a Ni free joint and of a joint with a $0.2 \mathrm{~mm}$ thick Ni interlayer, and histogram of the peak temperatures and times at the peak temperatures $v s$. the joint nature. As a reminder, thermocouple 1 is located in the steel HAZ and thermocouple 2 is in the cermet at the weld centre close to the interface.

Figure 5: Transverse cross-sections of the SC45 base steel etched with a) the Dino and b) the nital reagent (light microscopy), and of the WC-12Co cermet (c and d) (TEM). The bright phase in figures $\mathrm{c}$ and $\mathrm{d}$ is the Co binding phase.

Figure 6: a) Global top view of the joints $v s$. the Ni interlayer thickness; b) typical details of a joint top surface and c) of its half crowns (joint with a $0.1 \mathrm{~mm}$ thick Ni interlayer) (SE/SEM).

Figure 7: Details at the bottom of the keyhole a) and d) of the Ni-free joint (SE and BSE/SEM, respectively), b) and e) of the joint with a $0.1 \mathrm{~mm}$ thick Ni interlayer, c) and d) enlargement of the zones encircled in figures b) and e), respectively.

Figure 8: X-ray diffraction pattern showing the contamination of the pin due to welding.

Figure 9: a) Contamination detected on the flash at the border of the keyhole of the Ni free joint (BSE/SEM). b) Tool tip after welding. c) Numerous debris at the bottom of the joint keyhole with a $0.2 \mathrm{~mm}$ thick Ni interlayer. The insert depicts some agglomerates of $\mathrm{Si}_{3} \mathrm{~N}_{4}$ powder grains originating from the tool (BSE/SEM).

Figure 10: Transverse cross-sections of the different joints etched with the Benscoter and Marder reagent (light microscopy). BM and HAZ are the abbreviations for base material and heat affected zone, respectively.

Figure 11: Details of the processed zones in the transverse cross sections depicted in figure 10 for the Ni bearing joints with a $0.05 \mathrm{~mm}$ thick interlayer (a \&and b obtained with Leperra etchant), a $0.1 \mathrm{~mm}$ thickness (c, d, e, f \&and $g$ obtained with Benscoter and Marder etchant) and a $0.2 \mathrm{~mm}$ thickness (h obtained with Leperra etchant, $\mathrm{i}$ \&and $\mathrm{j}$ get with nital etchant and $\mathrm{k}$ get with Dino etchant) (light microscopy).

Figure 12: Ni-steel interface in the joint with a $0.2 \mathrm{~mm}$ thick Ni interlayer: a) interfacial zone with $\mathrm{Ni}$ grain and b) interfacial zone with a highly dislocated Ni grain (TEM, bright field images). The interdiffusion zone borders are deduced from the EDX analyses.

Figure 13: Interdiffusion between $\mathrm{Ni}$ and $\mathrm{Co}$ at the Ni-cermet interface in the joint with the $0.2 \mathrm{~mm}$ thickest $\mathrm{Ni}$ interlayer (STEM/EDX). Bright field micrograph, associated $\mathrm{Ni} \mathrm{K} \alpha$, Co $\mathrm{K} \alpha$ and $\mathrm{W}$ L $\alpha$ X-ray maps and EDX profile along the arrow drawn in the bright field image.

Figure 14: Transverse cross-section of the stirred surface of the Ni-free joint etched with the Leperrra reagent (light microscopy).

Figure 15: a) Microstructure in the transverse cross-section of the Ni-free joint etched with nital solution. b) Microstructure around the steel-Ni interface and Ni tongues in the transverse cross-section of the steel-cermet joint with a $0.05 \mathrm{~mm}$ thick Ni interlayer. The used Marder \&and Benscoter reagent takes advantage of coloring the retained austenite in white (yellow arrows) (light microscopy).

Figure 16: Transverse cross-sections micrographs of the steel nugget centre of the Ni free and Ni bearing joints etched with nital reagent (light microscopy). $\mathrm{M}$ is the abbreviation for martensite, RA for retained austenite, WF for Widmanstätten ferrite and LTP for low temperature pearlite.

Figure 17: Steel microstructure at a depth of $1 \mathrm{~mm}$ from the joint top surface in the Ni free joint (a, b and c: bright field images and associated electron diffraction patterns of zones referred as 1, 2 and 3 in micrograph a) and in the dissimilar joint with a $0.2 \mathrm{~mm}$ thick Ni filler (d: bright field image) (TEM). M is the abbreviation for martensite and LTP for low temperature pearlite. 
Figure 18: Typical micrographs of the HAZ in the advancing (a) and retreating (b) sides (transverse cross sections, nital etching, light microscopy). RA is the abbreviation for retained austenite, WF for Widmanstätten ferrite, $\mathrm{B}$ for bainite, $\mathrm{M}$ for martensite and LTP for low temperature pearlite.

Figure 19: X-ray diffraction patterns of the Ni-free and Ni bearing joints.

Figure 20: Ni-steel interface in the joint with a $0.2 \mathrm{~mm}$ thick $\mathrm{Ni}$ interlayer: dynamic recovery in $\mathrm{Ni}$.

Figure 21: Interdiffusion between $\mathrm{Fe}$ and $\mathrm{Co}$ at the steel-cermet interface in the Ni-free joint (STEM/EDX). Bright field micrograph, associated $\mathrm{Fe} \mathrm{K} \alpha$, $\mathrm{Co} \mathrm{K} \alpha$ and $\mathrm{W} \mathrm{L} \alpha \mathrm{X}$-ray maps and EDX profile along the arrow drawn in the bright field image.

Figure 22: Interdiffusion between $\mathrm{Fe}$ and $\mathrm{Ni}$ at the steel-Ni interface in the joint with the $0.2 \mathrm{~mm}$ thick $\mathrm{Ni}$ interlayer (STEM/EDX). Bright field micrograph, associated $\mathrm{Fe} \mathrm{K} \alpha$ and $\mathrm{Ni} \mathrm{K} \alpha \mathrm{X}$-ray maps and EDX profiles along the arrows drawn in the bright field image.

Figure 23: Microhardness maps of the transverse cross-sections of the different joints (plane X-Y).

Figure 24: Typical shear-lap tensile curves for the Ni free and Ni bearing joints.

Figure 25: a) Maximum shear-lap force and displacement vs. the Ni layer thickness and b) energy consumed for the total fracture of the various joints.

Figure 26: Fracture surfaces of the joints (SE/SEM micrographs). 